\title{
When semantics means less than morphology: The processing of German prefixed verbs
}

\author{
Eva Smolka \\ Philipps-University, Marburg, Germany and University of La Laguna, \\ La Laguna, Spain \\ Sarolta Komlósi and Frank Rösler \\ Philipps-University, Marburg, Germany
}

This study investigated whether form and meaning relatedness modulate the processing of morphologically related German verbs. In two overt visual priming experiments, we compared responses for verb targets (kommen, come) that were preceded by a purely semantically related verb (nahen, approach), by a morphologically and semantically related verb (mitkommen, come along), by a purely morphologically related verb (umkommen, perish), or by an unrelated verb (schaden, harm). In Experiment 1, morphological relatedness produced robust facilitation, which was not influenced by semantic relatedness. Moreover, this morphological facilitation was far stronger than the priming by purely semantically related verbs. In Experiment 2, orthographically similar primes (kämmen, comb) produced interference effects and thus indicated that the morphological facilitation effects were not the result of sheer form overlap between primes and targets. These findings argue for a single system that processes morphological relations independently of form and meaning relatedness.

Correspondence concerning this article should be addressed to Eva Smolka, Department of Psychology, University of La Laguna, Campus de Guajara, 38205 La Laguna, Tenerife, Spain. E-mail: esmolka@ull.es

This study was supported by the German Research Foundation (DFG), grant For 254/2 to Frank Rösler, and was partially funded by grant MTKD-CT-2005-029639 from the European Commission.

We thank Pienie Zwitserlood, Stefan Rabanus, Matthias Gondan, Joana Cholin, and two anonymous reviewers for helpful comments. We thank Mihal Raveh for her help with the Hebrew examples. 
The morphological structure of a word plays a major role in language processing. For example, the word Fachbereichsratssitzung (meeting of the faculty council) is probably not represented as a single lexical entry in the mental lexicon of most native German speakers, unless they frequently attend such meetings. Nonetheless, the morphological regularities of the German language will provide the additive meanings of fach (subject), bereich (domain), rat (council), sitz (sit), and ung (suffix denoting a noun) to derive the meaning of the whole word. ${ }^{1}$

Indeed, most psycholinguistic models agree that morphological regularities determine visual word recognition (e.g., Frost, Forster, \& Deutsch, 1997; Marslen-Wilson, Tyler, Waksler, \& Older, 1994; Plaut \& Gonnerman, 2000; Schreuder \& Baayen, 1995; Stolz \& Feldman, 1995). However, these models differ on the assumption of whether morphological processing is independent of semantic and form processing, and whether morphological units are explicitly represented in the mental lexicon.

A traditional means to dissociate morphological and semantic processing has been the manipulation of semantic transparency between morphologically related words. The priming of a word like think by a morphologically related and semantically transparent word like rethink can be attributed to both morphological and semantic processing, since the meaning of its morphemic constituents re-and think derive the meaning of the whole word. By contrast, the facilitation of a target like treat by a semantically opaque prime like retreat whose meaning cannot be derived from the meaning of its parts can disentangle morphological and semantic processing. Such priming would represent morphological processing that is independent of semantic processing, and would thus provide evidence that the words treat and retreat share some lexical representation (be it localised or distributed) in spite of their opaque meaning relation.

A seminal study of Bentin and Feldman (1990) demonstrated the dissociation between semantic and morphological processing in Hebrew. Purely semantically related primes facilitated targets only when they immediately succeeded the prime, whereas morphological priming effects lasted over long word lags as well. Moreover, the recognition of a target like migdal (tower) was primed by morphologically related words (via the root $g d l$ ) regardless of whether they were semantically related like gadol (big) or semantically unrelated like gidul (tumour).

Further studies in Hebrew and Arabic replicated robust priming by both semantically transparent and opaque derivations. Morphological priming was stable across different stimulus onset asynchronies (SOA) in the masked priming paradigm (Boudelaa \& Marslen-Wilson, 2005; Deutsch, Frost, \&

\footnotetext{
${ }^{1}$ The linking element $-s$ - is inserted in compounds to maintain the morphological structure. For a discussion on the functions of linking elements see Wegener (2003).
} 
Forster, 1998; Frost et al., 1997), and by using cross-modal priming (Boudelaa \& Marslen-Wilson, 2004a, 2004b; Frost, Deutsch, Gilboa, Tannenbaum, \& Marslen-Wilson, 2000). These findings were taken as evidence that in Semitic languages the morphemic constituents of a word represent essential processing units regardless of meaning.

In English and French, however, findings on morphological priming have not been straightforward and have depended on procedural details, such as prime modality and prime duration. Under experimental conditions, in which the prime is consciously perceived, that is, under cross-modal priming (Longtin, Segui, \& Hallé, 2003; Marslen-Wilson et al., 1994) and visual priming at long SOAs (230 ms or $250 \mathrm{~ms}$; Feldman \& Soltano, 1999; Feldman, Soltano, Pastizzo, \& Francis, 2004; Rastle, Davis, Marslen-Wilson, \& Tyler, 2000), the semantic relatedness between prime and target was a precondition for the occurrence of morphological priming: The recognition of stems like success was not facilitated by morphologically related but semantically opaque derivations like successor. Only semantically transparent derivations like confessor primed related stems like confess.

In addition to the semantic relatedness between primes and targets, under such overt prime presentations, the modality of prime-target presentation and the affixation type, that is, whether primes and targets were prefixed or suffixed derivations, has also influenced morphological priming effects. Under visual and cross-modal priming presentations, English and French prefixed derivations like distrust primed their semantically related stems like trust, as well as other prefixed or suffixed derivations like entrust or trustful (Feldman \& Larabee, 2001; Marlsen-Wilson et al., 1994; Meunier \& Segui, 2002). Also French suffixed derivations like production and productivité primed each other under cross-modal presentations (Meunier \& Segui, 2002), whereas English suffixed derivations like confession and confessor did not prime each other under cross-modal presentations, though they did under visual presentations (Feldman \& Larabee, 2001; Feldman et al., 2004; Marslen-Wilson et al., 1994).

In English and French, evidence for morphological priming without a semantic relation has occurred only under conditions in which the participants were not aware of the existence of a prime. Under masked visual priming (with SOAs under $50 \mathrm{~ms}$ ), semantically opaque words primed morphologically related targets to the same degree as semantically transparent words (Longtin et al., 2003; Rastle et al., 2000; Rastle, Davis, \& New, 2004). However, in a study with short but unmasked prime presentations, neither semantically transparent nor opaque words induced significant morphological priming (Feldman et al., 2004).

On the whole, morphological priming effects in English and French have proved to be subject to semantic transparency, affixation type, priming technique, and time course, whereas morphological priming in Hebrew and 
Arabic have proved to be fairly independent of semantic effects and stable across priming paradigms and time course. Two structural characteristics of a language, its linearity and its morphological richness, have been drawn on to explain why morphological processing seems crucial in some languages but not in others.

\section{LINEARITY OF A LANGUAGE}

In languages with concatenative morphology like English or French, morphemes are appended to one another in a linear fashion. In contrast, in Semitic languages like Hebrew and Arabic, words comprise two abstract morphemes, the root and the word pattern, which are intertwined one within the other. ${ }^{2}$ The root conveys the semantic meaning of the word, while the word pattern carries phonological and morpho-syntactic information. Both the root and the word pattern are abstract, discontinuous morphemes dispersed in the word, and neither the root nor the word pattern provides sufficient meaning without the other. For example, the root spr (relating to 'count' and 'recount') inserted in different word patterns derives Hebrew words like sefer (book), sifria (library), and mispar (number).

The different findings on morphological priming effects across languages - restricted to semantic transparency in English and French but independent of semantic compositionality in Hebrew and Arabic - gave rise to the assumption that the linearity of a language may influence the representation of morphological units (Frost et al., 2000): Since every Hebrew or Arabic word is at least bimorphemic and requires the extraction of the root from the word pattern, speakers of Hebrew and Arabic may automatically decompose words into their underlying constituent morphemes, regardless of the semantic compositionality of the word (Boudelaa \& Marslen-Wilson, 2005; Frost et al., 2000). In English, semantic transparency effects were interpreted to indicate that a semantically opaque word like successor is probably not perceived as a derived word and is rather represented as an unanalysed separate lexical item that does not share a stem with words like success or successful (Marslen-Wilson et al., 1994). That is, in linear languages like English and French, decomposition might rely heavily on semantic compositionality, while in nonlinear languages like the Semitic languages, decomposition might be an obligatory necessity that is thus not determined by semantic compositionality.

\footnotetext{
${ }^{2}$ For a discussion on whether the root or the etymon constitutes the basic unit see Boudelaa and Marslen-Wilson (2001).
} 


\section{MORPHOLOGICAL RICHNESS OF A LANGUAGE}

In contrast to the linearity notion, distributed-connectionist approaches (Plaut \& Gonnerman, 2000; Rueckl, Mikolinski, Raveh, Miner, \& Mars, 1997) assume that the morphological richness of a language determines whether or not morphological processing is affected by semantic transparency.

According to a distributed approach, morphological relations are indirectly represented by the systematic mapping between orthographic forms and their meaning. In a morphologically impoverished language like English, mappings between orthographic surface forms and their meaning are mostly idiosyncratic, so that morphological regularities may contribute little to language processing. On the other hand, in morphologically rich languages like Hebrew and Arabic, mappings between orthographic form and meaning are straightforward. As soon as systematic form-to-meaning regularities dominate language processing, morphological effects will occur that are independent of semantic transparency.

Generally speaking, both the structure of a language and the morphological richness of a language may determine the occurrence of semantic transparency effects. Based on the contrast between English (concatenative, morphologically impoverished) and Hebrew (nonconcatenative, morphologically rich), cross-linguistic differences can be attributed to either of these two factors. The present study used German as a test language to examine whether semantic transparency affects morphological processing. German is of particular interest, since it is both a concatenative and a morphologically rich language, as the pervasiveness of prefixed verbs (described below) illustrates. If language linearity determines the presence or absence of semantic transparency effects on morphological processing, morphological priming effects in German should be influenced by semantic transparency. However, if the morphological richness of a language is the crucial factor for the occurrence of semantic influences, German should yield morphological priming effects that are independent of semantic transparency. We thus asked whether morphological priming effects in German resemble those in other concatenative languages like English and French or those in other morphologically rich languages like Hebrew and Arabic.

\section{GERMAN PREFIXED VERBS}

German prefixed verbs provide the opportunity to manipulate the semantic transparency and opacity relating to the same base verb. The following derivations of the verb kommen (come) illustrate the wide range of meaning variation - from fully transparent to fully opaque - with regard to the same base verb: ankommen (arrive), mitkommen (come along), zurückkommen 
(come back), nachkommen (follow), entkommen (escape), abkommen (digress), bekommen (get), verkommen (degenerate), and umkommen (perish).

Unlike in English, where most prefixes are of Greek or Latin origin (e.g., de-, ex-, in-, re-, per-, sub-), the abundant German verbal prefixes are mostly of Germanic origin. The linguistic literature (e.g., Olsen, 1996) distinguishes two word formations under the heading of prefixed verbs: prefix verbs and particle verbs. Both types comprise a simple verb and a prefix or a particle. Yet, prefixes like ver-and be- are bound morphemes that do not necessarily have a meaning of their own, while particles like mit (with) and um (around) are free morphemes in the function of prepositions or adverbs and are separated from the verb stem in finite forms. In spite of these syntactic differences, both prefix and particle verbs may be both transparently and opaquely related to the meaning of their base verbs. For example, the particle um (around) may produce a transparent derivation like umgehen (go around) of the base verb gehen (go), and an opaque derivation like umkommen (perish) of the verb kommen (come). Similarly, the prefix ver- results in the prefix verb verbleiben (remain) that is transparently related to its base verb bleiben (stay), but may also produce a verb like verschwimmen (blur) that is opaquely related to its base schwimmen (swim). Moreover, effects for prefix and particle verbs in German (Drews, Zwitserlood, \& Neuwinger, 2000) and Dutch (Schriefers, Zwitserlood, \& Roelofs, 1991) were found to be alike, so that these types are not further differentiated in the present study (and are subsumed under the general term 'prefixed verbs').

We used prefixed verbs in the present experiments to study semantic transparency effects on morphological processing. Effects of semantic transparency and semantic association are difficult to detect in either the masked or the long-term priming task, whereas in the immediate repetition priming paradigm, semantic effects among morphological relatives tend to increase with SOA (for a review see Feldman et al., 2004; Feldman \& Prostko, 2002; Raveh \& Rueckl, 2000). To ensure that the experimental conditions of the present study were sensitive to semantic processing, we applied an immediate repetition priming paradigm with visual prime presentations at long SOAs (300 $\mathrm{ms}$ in Experiments 1 and $2 \mathrm{a}$, and 1000 $\mathrm{ms}$ in Experiment 2b).

\section{EXPERIMENT 1}

In Experiment 1, we examined the effects of semantic relatedness on morphological processing. For this purpose, we compared the priming effects of morphologically related verbs that were either semantically transparent $(+\mathrm{M}+\mathrm{S}$, mitkommen, come along) or semantically opaque ( $+\mathrm{M}-\mathrm{S}$, umkommen, perish) with regard to their base verb (kommen, 
come). To measure the effect of semantic relatedness without morphological relation, semantically related but morphologically unrelated primes $(-\mathrm{M}+$ $\mathrm{S}$, nahen, approach) were introduced as well. This design allowed us (a) to disentangle semantic from morphological effects on the same verb target, and (b) to directly compare semantic transparency effects with regard to the same base verb. The facilitation obtained by semantically and/or morphologically related primes was measured relative to verbs that were both semantically and morphologically unrelated to the target (schaden, harm).

In addition, an identity condition (kommen, come) provided an estimation of the maximal priming effect. Whether or not prime and target activate the same base has traditionally been tested by comparing 'full' priming (identity priming) with 'partial' priming (less than identity priming). In a seminal study, Stanners, Neiser, Hernon, and Hall (1979) found that regular past tense forms like poured primed their uninflected base verbs like pour just as well as did the identical prime pour. Also, derivational primes facilitated responses to their base verbs, that is, predictable primed predict, but to a lesser extent than predict primed predict. Stanners et al. (1979) inferred two types of memory representations: one, in which the base verb represents the lexical entry of all related forms and thus receives 'full' activation when another form is accessed; the other comprises separate lexical entries for the base verb and its related forms. Since the activation needs to spread between them, it is 'partial'.

However, subsequent studies (Fowler, Napps, \& Feldman, 1985; Napps, 1989) found both 'full' and 'partial' priming between derivationally related words, depending on whether or not the derived forms preserved the sound and/or spelling of the base verb (e.g., manager priming manage; assumption priming assume).

In the present study, a comparison with the identity condition should reveal whether semantic or morphological priming is 'full' or 'partial' priming, that is, whether the same or different base verbs are activated by prime and target. To keep the syntactic class of primes and targets constant, only verbs were used as experimental stimuli.

\section{Method}

\section{Participants}

Twenty-seven students of the Philipps-University, Marburg, participated in the experiment for course credit or payment. All participants were monolingual speakers of German, not dyslexic, and had normal or corrected-to-normal vision. 


\section{Materials}

Critical stimuli. Thirty-six simple verbs were selected as critical targets, each was combined with five types of primes: (a) an identical prime (kommen, come), (b) a semantically related but morphologically and orthographically unrelated prime $(-\mathrm{M}+\mathrm{S}$, nahen, approach), (c) a morphologically related and semantically transparent prime $(+\mathrm{M}+\mathrm{S}$, mitkommen, come along), (d) a morphologically related but semantically opaque prime ( $+\mathrm{M}-\mathrm{S}$, umkommen, perish), and (e) a semantically, morphologically, and orthographically unrelated prime (U, schaden, harm). In total, 180 critical prime-target pairs were created, 108 had unprefixed verb primes, 72 had prefixed verb primes. The prefixed variants included both particle verbs and prefix verbs. All primes (except for identity primes) were less frequent than their targets. Stimulus characteristics including mean surface frequency, mean lemma frequency, mean word length, and mean relatedness scores of primes and targets are summarised in Table 1.

This critical set of 180 prime-target pairs was selected from a pool of verb pairs that were subjected to the semantic relatedness test described below.

Semantic relatedness test. The final set of 36 critical targets was chosen from among 52 candidate verbs. All were monomorphemic German verbs (e.g., kommen, come) from the CELEX German lexical database (Baayen, Piepenbrock, \& van Rijn, 1993), all without prefix. For the morphologically related conditions $(+\mathrm{M}+\mathrm{S}$ and $+\mathrm{M}-\mathrm{S})$, these verbs were combined with several morphologically related prefixed variants (e.g., nachkommen, follow; mitkommen, come along; verkommen, degenerate; umkommen, perish). All of them were listed in a German monolingual dictionary (Duden, 2003).

TABLE 1

Stimulus characteristics of primes that were semantically related $(-M+S)$, morphologically and semantically related $(+M+S)$, morphologically related $(+M-S)$, or unrelated to targets in Experiment 1

\begin{tabular}{lcccc}
\hline & $\begin{array}{c}\text { Surface } \\
\text { frequency }\end{array}$ & $\begin{array}{c}\text { Lemma } \\
\text { frequency }\end{array}$ & Word length & Relatedness score \\
\hline Target kommen (come) & 98.1 & 355.2 & 6.6 & - \\
- M +S nahen (approach) & 40.2 & 143.8 & 6.7 & 6.2 \\
+ M + S mitkommen (come along) & 2.3 & 11.7 & 10.1 & 5.4 \\
+ M -S umkommen (perish) & 3.4 & 17.6 & 9.6 & 2.2 \\
Unrelated schaden (harm) & 12.7 & 75.4 & 6.6 & 1.5 \\
& & & & \\
\hline
\end{tabular}

Note. Statistics are given for the total set of stimuli, sample stimuli are italicised. All frequencies are from the CELEX database (Baayen et al., 1993), count is per million. Targets correspond to identity primes. 
In addition, all simple verbs were paired with a semantically related but morphologically unrelated verb $(-\mathrm{M}+\mathrm{S}$, nahen, approach) as well as with a verb that was neither semantically nor morphologically related (U, schaden, harm).

Morphologically and/or semantically related prime-target pairs were distributed across five lists. Unrelated prime-target pairs were added to each list, so that each list included one unrelated and one related primetarget pair of the same verb. In total, 430 prime-target pairs were tested, each list comprised 85 or 86 pairs. All verbs were presented in the citation form (stem $+-e n)$, and the verb intended as the prime preceded the target. The five lists were distributed to 50 native speakers of German who did not participate in the main experiment. They rated the meaning relation between the verbs of each pair on a 7-point scale from completely unrelated (1) to highly related (7).

The following criteria determined whether a simple verb was included in the critical set, and which of its prefixed variants was chosen: No pair with a mean rating score of less than 4 was included in any of the semantically related conditions $(-\mathrm{M}+\mathrm{S}$ and $+\mathrm{M}+\mathrm{S})$, no pair with a rating higher than 3.5 was included in the semantically opaque condition $(+\mathrm{M}-\mathrm{S})$, and no pair with a rating higher than 2.5 was included in the unrelated condition (U).

The mean rating scores of the final set were 6.2 in the semantically related condition, 5.4 in the morphologically and semantically related condition, 2.2 in the morphologically related but semantically unrelated condition, and 1.5 in the unrelated condition. A one-way ANOVA was performed on mean rating scores with items $\left(F_{2}\right)$ as random variables. The repeated measures factor Prime Type $(-\mathrm{M}+\mathrm{S} /+\mathrm{M}+\mathrm{S} /+\mathrm{M}-\mathrm{S} /$ unrelated $)$ was significant, $F_{2}(3,105)=879.73, p<.0001$. Scheffé post hoc comparisons confirmed that all conditions differed significantly from each other.

Filler prime-target pairs. In total, 1020 filler pairs were added to the 180 critical pairs. In order to have a closely matched pseudoverb set, 180 primetarget pairs were created with pseudoverb targets that were orthographically and phonologically similar to the 36 simple verbs of the critical set. For example, the pseudoverbs hogen, holken, hollern, holsen, and holpfen were created to be similar to the verb holen (fetch). Primes followed the same composition as those of the experimental set: 72 were prefixed, 108 were unprefixed verbs. Additional 840 filler prime-target pairs were included, 420 with verb targets and 420 with pseudoverb targets. In each set of verb and pseudoverb targets, 120 verb primes were prefixed and 300 were unprefixed. All pseudoverbs obeyed the phonotactic constraints of the German language. All filler items differed from items of the critical set. 
Relatedness proportions. The material set consisted of 180 critical primetarget pairs, of which 144 (in the $-\mathrm{M}+\mathrm{S},+\mathrm{M}+\mathrm{S}$, $+\mathrm{M}-\mathrm{S}$, and Identity conditions) were semantically and/or morphologically related. By definition, all 72 prefixed primes (in the $+\mathrm{M}+\mathrm{S}$ and $+\mathrm{M}-\mathrm{S}$ conditions) were related to the verb target, such as in mitkommen - kommen. Napps and Fowler (1987) showed that a reduction in the proportion of related items from $75 \%$ to $25 \%$ reduced both facilitatory and inhibitory effects. A significant reduction of related items in the present study should discourage participants from expecting a particular related verb target and thus prevent both expectancy and failed expectancy effects. Hence, 1020 filler prime-target pairs were included: 312 with prefixes and 708 without prefixes. All were semantically unrelated; 72 of the prefixed and 108 of the unprefixed primes were followed by a form-related pseudoverb. The insertion of form-related pseudoverbs should deter participants from 'automatically' responding with a 'word' response whenever they saw a form-related target.

Overall, the large amount of fillers reduced (a) the critical prime-target pairs to $15 \%$ of the entire material set, (b) the proportion of related pairs to $12 \%$ of the material, (c) the amount of prefixed primes that were followed by a related target to $18.75 \%$, and (d) the amount of unprefixed primes followed by a related target to $9 \%$.

To summarise, the whole material set comprised 1200 prime-target pairs, 180 critical and 1020 filler prime-target pairs. Half of the 1200 prime-target pairs comprised verb targets, the other half pseudoverb targets. Primes were always existing verbs. All primes and targets were presented in the infinitive $($ stem $+-e n)$, which is also the citation form in German.

\section{Apparatus}

Stimuli were presented on a 17" monitor, connected to an IBMcompatible Pentium III personal computer. Stimulus presentation and data collection were controlled by the Presentation software developed by Neurobehavioral Systems (http://nbs.neuro-bs.com/). Response latencies were recorded from the left and right 'control' keyboard keys.

\section{Design}

Each participant saw all 36 simple verbs in all five priming conditions. Primes of the same target were rotated over five blocks according to a Latin Square design. Likewise, the prime-target pairs of similar pseudoverb targets were distributed across the five blocks. The remaining filler pairs were evenly allocated to the blocks, so that each block comprised equal numbers of prefixed and unprefixed primes as well as verb and pseudoverb targets.

In total, an experimental session comprised 1200 prime-target pairs, presented in five experimental blocks, with 240 prime-target pairs per block. 
Within blocks, prime-target pairs were randomised separately for each participant. There were 20 practice trials.

\section{Procedure}

Participants were tested individually in a dimly lit room and were seated at a viewing distance of about $60 \mathrm{~cm}$ from the screen. Each trial started with a fixation cross in the centre of the screen for $1000 \mathrm{~ms}$. The prime appeared for $200 \mathrm{~ms}$, followed by a blank screen for $100 \mathrm{~ms}(\mathrm{SOA}=300)$. Then the target appeared for $500 \mathrm{~ms}$. The intertrial interval was $2000 \mathrm{~ms}$.

Primes and targets were presented in the centre of the screen, in white Sans Serif letters on a black background. Primes were presented in uppercase letters, point 19, targets in lowercase letters, point 20.

Participants made lexical decisions to the targets, and were instructed to respond as fast and as accurately as possible. 'Word' responses were made by pressing one of the 'control' keyboard keys with the index finger of the dominant hand, 'pseudoword' responses were made with the subordinate hand. During practice trials, participants received feedback on the correctness of each response; during the experimental session only on incorrect responses.

The experiment lasted for about two hours. Participants self-administered the breaks between blocks, and were asked to take at least two longer breaks.

\section{Results}

Analyses were performed with participants $\left(F_{1}\right)$ and items $\left(F_{2}\right)$ as random variables. Only reaction times (RTs) within two standard deviations from a participant's mean were included in the data analyses. Mean response latencies were calculated for correct responses; mean error rate was $3.3 \%$. Uncorrelated RT and error means over participants, $r=.05625, p=.3827$, indicated that there was no speed-accuracy trade-off. RT and error means are summarised in Table 2, the corresponding priming effects are depicted in the upper panel of Figure 1.

A one-way ANOVA with the repeated measures factor Prime Type (identity/ $-\mathrm{M}+\mathrm{S} /+\mathrm{M}+\mathrm{S} /+\mathrm{M}-\mathrm{S} /$ unrelated) was performed on RT and error means. The effect was significant for RT data, $F_{1}(4,104)=35.80, p<$ $.0001 ; F_{2}(4,140)=23.42, p<.0001$, but not for error data $\left(F_{1}\right.$ and $\left.F_{2}<1\right)$.

The contrast between unrelated primes and identity primes (representing no priming and the maximal amount of priming, respectively) was highly significant, $F_{1}(1,104)=99.31, p<.0001 ; F_{2}(1,140)=63.14, p<.0001$, and confirmed that identity primes yielded faster responses than unrelated primes.

First, related conditions were contrasted with the unrelated control condition to establish whether semantic or morphological facilitation 
TABLE 2

Response latencies and accuracies of Experiment 1

\begin{tabular}{lllc}
\hline Prime type & $R T(S D)$ & Effect & Error \\
\hline Identity kommen (come) & $556(111)$ & $51^{* * * * *}$ & 0.8 \\
$-\mathrm{M}+\mathrm{S}$ nahen (approach) & $598(116)$ & $(9)$ & 0.7 \\
$+\mathrm{M}+\mathrm{S}$ mitkommen (come along) & $567(113)$ & $40^{* * * *}$ & 1.3 \\
$+\mathrm{M}-\mathrm{S}$ umkommen (perish) & $572(120)$ & $35^{* * * *}$ & 1.3 \\
Unrelated schaden (harm) & $607(114)$ & 0.8 & \\
\end{tabular}

Note. Mean RTs in milliseconds (SD) and mean percentage of errors for verb targets like kommen (come) preceded by identical primes, by semantically related primes $(-\mathrm{M}+\mathrm{S})$, by morphologically related primes that were either semantically transparent $(+M+S)$ or semantically opaque $(+\mathrm{M}-\mathrm{S})$, or by unrelated primes. Priming effects are calculated in contrast to the unrelated condition. $* * * * p<.0001$ indicates significance levels for both participants and items analyses.

occurred. Purely semantically related primes did not facilitate responses relative to unrelated primes, $F_{1}(1,104)=2.86, p=.0936 ; F_{2}(1,140)=1.75$, $p=.1886$. In contrast, morphologically related prefixed verbs significantly facilitated target recognition relative to the unrelated prime condition. This was true for both semantically transparent primes, $F_{1}(1,104)=61.45, p<$ $.0001 ; F_{2}(1,140)=42.21, p<.0001$, and semantically opaque primes, $F_{1}(1$, $104)=46.43, p<.0001 ; F_{2}(1,140)=29.92, p<.0001$. Even more so, there was no difference between the facilitation yielded by semantically opaque verbs $(35 \mathrm{~ms})$ and that by semantically transparent verbs $(40 \mathrm{~ms}), F_{1}(1$, $104)=1.05, p=.3079 ; F_{2}(1,140)=1.05, p=.3062$, indicating that morphological priming was not influenced by the semantic relation between primes and targets.

Second, the morphologically related conditions were contrasted with the identity control condition, which is assumed to produce maximal priming. Facilitation for verb targets that were primed by themselves was significantly greater than the facilitation by morphologically related verbs. Regarding semantically opaque primes, the contrast was significant by both participants and items, $F_{1}(1,104)=9.93, p=.0021 ; F_{2}(1,140)=6.13, p=.0145$. For semantically transparent primes, the contrast was significant by participants, $F_{1}(1,104)=4.52, p=.0358$, but not by items, $F_{2}(1,140)=$ $2.10, p=.1495$.

\section{Discussion of results}

The aim of Experiment 1 was to test whether morphological priming effects in German are modulated by semantic transparency. For this purpose, we compared responses for the same verb target when it was preceded by transparently or opaquely related prefixed verbs. Results were straightforward: 

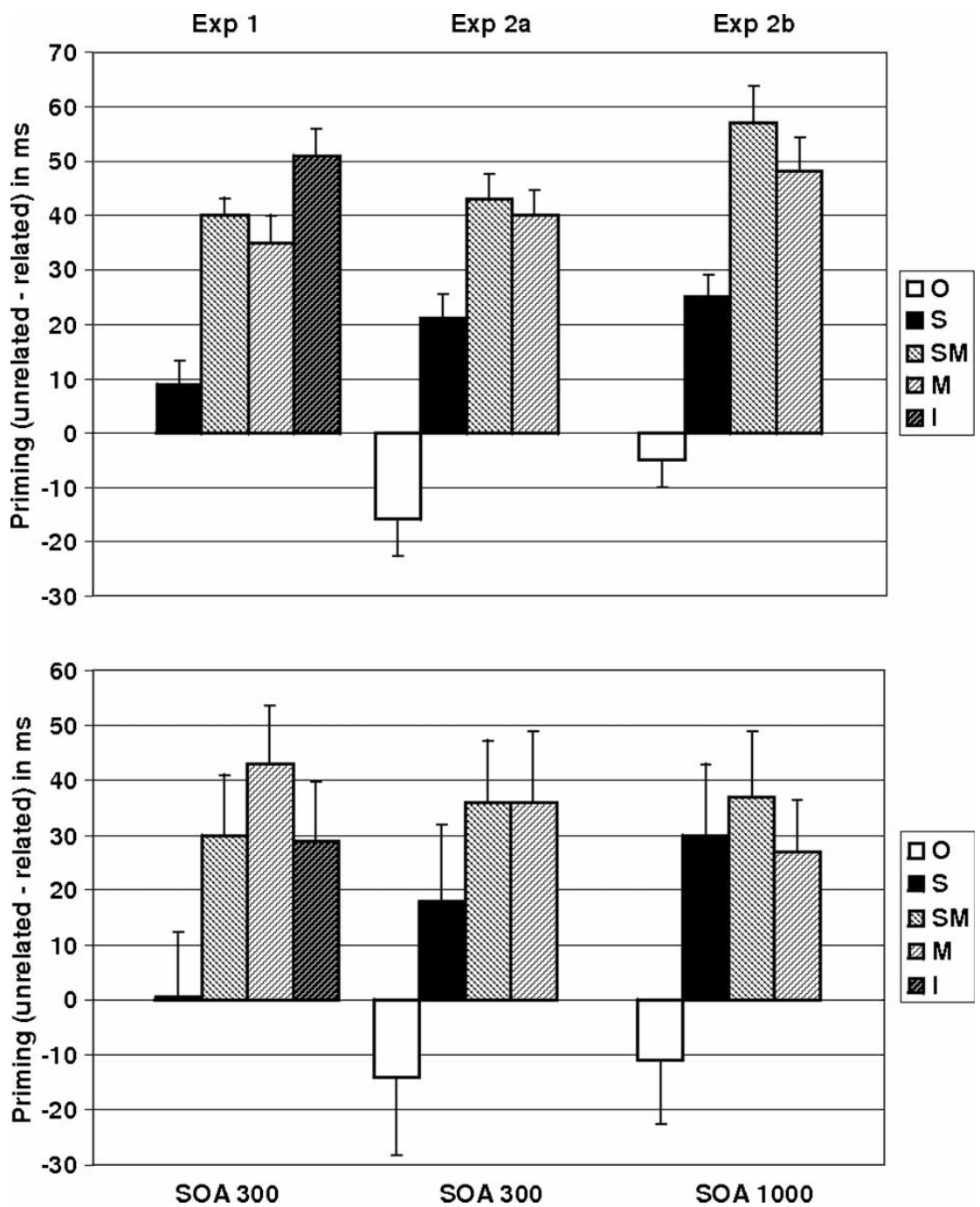

Figure 1. Semantic (S), semantically transparent (SM), semantically opaque (M), identity (I), or orthographic priming effects (relative to unrelated words) in Experiment 1 (SOA 300), Experiment 2a (SOA 300), and Experiment 2b (SOA 1000). Effects of the overall analyses are depicted in the upper panel, effects of the first-block analyses in the lower panel. The y-bars provide the standard errors of the means.

We found strong morphological priming effects that were not modulated by semantic transparency. That is, the $35 \mathrm{~ms}$ facilitation induced by semantically opaque prefixed verbs like umkommen (perish) on a base verb like kommen (come) was as strong as the $40 \mathrm{~ms}$ facilitation by semantically transparent verbs 
like mitkommen (come along). The magnitude of these morphological effects was nevertheless weaker than the priming observed for identical prime-target pairs $(51 \mathrm{~ms})$. A detailed comparison of the morphological and the identity priming effects is provided in the post-hoc analyses (see below).

In contrast to the strong morphological effects, there was no semantic facilitation $(9 \mathrm{~ms})$ between meaning-related verbs like nahen (approach) and kommen (come). Such a lack of semantic facilitation is surprising given that the meaning association between primes and targets was fully apparent, as indicated by the ratings of the semantic association (see Table 1 for rating scores). In contrast, semantically opaque prime-target pairs produced a strong and reliable priming effect, even though they were rated as being semantically unassociated. It thus seems that offline ratings are mostly affected by semantic associations, whereas online processing is dominated by morphological relations.

The morphological effects could, however, have been the result of form similarity rather than of morphological relatedness. Naturally, words that share a morphological structure are also similar in form. Identity primes like kommen (come) shared the exact form of the targets like kommen. Also morphologically related primes - both transparent ones like mitkommen (come along) and opaque ones like umkommen (perish) - comprised the complete target word and thus shared its form. In contrast, semantically related primes like nahen (approach) and unrelated primes like schaden (harm) did not overlap in form with the target except for the infinitive suffix -en. The magnitude of the priming effects found in Experiment 1 could thus reflect a continuum of shared form between primes and targets: the largest priming effect for pairs with the identical form overlap, followed by morphologically related pairs, and weak priming between pairs that do not share any form, namely semantically related pairs. Since both semantically transparent and opaque primes comprised the whole verb target and thus equally overlapped in form with the target, this could explain why these two morphological conditions produced equal amounts of priming.

\section{EXPERIMENT 2}

Experiment 2 included an orthographic control condition to discount the possibility that the morphological priming effects found in Experiment 1 were the result of form similarity between primes and targets. Recent evidence has accumulated that mere form overlap between primes and targets produces different priming effects than the effects observed for morphological relatedness. For example, under cross-modal priming conditions (Gonnerman, Seidenberg, \& Andersen, 2000; Marslen-Wilson et al., 1994), morphologically unrelated but form related primes like planet did not 
facilitate the recognition of a target like plan. In contrast, morphologically related pairs produced robust priming regardless of whether they underwent phonetic change or not (friendly - friend, tension - tense or vanity - vain).

When targets immediately followed visually presented primes, the direction of the orthographic effects depended on prime duration: At short SOAs (between $32 \mathrm{~ms}$ and $66 \mathrm{~ms}$ ), orthographic similarity of the prime most often facilitated the recognition of the target (Feldman, 2000; Giraudo \& Grainger, 2000; Rastle et al., 2000; Segui \& Grainger, 1990). However, delays of target recognition were also found (Drews \& Zwitserlood, 1995; Grainger, Colé, \& Segui, 1991; Segui \& Grainger, 1990). At long SOAs (of $230 \mathrm{~ms}$ or more), that is, under prime conditions similar to the ones used in the present study, orthographically similar primes repeatedly inhibited the recognition of the target (Drews \& Zwitserlood, 1995; Feldman, 2000; Feldman \& Andjelkovic, 1992; Grainger, 1990; Pastizzo \& Feldman, 2002; Rastle et al., 2000; Segui \& Grainger, 1990).

Experiment 2 included as form controls verbs like kämmen (comb) that were orthographically similar but neither semantically nor morphologically related to the corresponding target like kommen (come). Since morphologically related primes comprised the verb's base and a prefix, one may argue that a preferred form control for the morphological primes would consist of the verb's base and a nonmorphological beginning. However, such verbs do not exist in German. In order to control for the confounding variable of word category, we found it crucial to have all primes and targets as verbs.

First, the orthographic condition was compared with the unrelated condition to indicate whether orthographically similar primes facilitated or inhibited target recognition. Second, a comparison between the orthographic condition and the morphologically related but semantically unrelated condition ( $+\mathrm{M}-\mathrm{S}$, umkommen, perish) would indicate whether orthographic priming differs from morphological priming. In both conditions, by definition, primes and targets are unrelated in meaning in spite of their form overlap. A contrast of these two conditions would thus measure the effects of form similarity without the confounding effects of meaning relation. Furthermore, this comparison allows examination of the influence of morphemic constituents as processing units: Morphemes, by definition, map form units to meaning units, however, these mappings are independent of the form-to-meaning mapping of the whole words to which the morphemic units belong.

As in Experiment 1, a semantically related but morphologically unrelated condition $(-\mathrm{M}+\mathrm{S}$, nahen, approach) was used to measure the amount of pure semantic relatedness.

To summarise, in Experiment 2, an orthographically related priming condition was added to the semantically and morphologically related priming conditions used in Experiment 1. To provide the same experimental 
conditions as in Experiment 1, visual primes were presented at an SOA of $300 \mathrm{~ms}$ in Experiment 2a. Experiment $2 \mathrm{~b}$ was conducted to examine whether prolonged SOAs of $1000 \mathrm{~ms}$ would stimulate the emergence of semantic effects beyond morphological effects.

\section{Method}

\section{Participants}

Fifty-two students of the Philipps-University, Marburg, participated in the experiment for course credit or payment, 25 in Experiment 2a and 27 in Experiment $2 b$; none had taken part in the first experiment. All participants were monolingual speakers of German, not dyslexic, and had normal or corrected-to-normal vision.

\section{Materials}

Critical stimuli. The experimental set included the same 36 simple verbs as used in Experiment 1. Each verb target, such as kommen (come), was combined with five different prime conditions: The semantically related $(-\mathrm{M}+\mathrm{S})$, and the two morphologically related $(+\mathrm{M}+\mathrm{S},-\mathrm{M}+\mathrm{S})$ priming conditions were the same as in Experiment 1. The unrelated primes were selected to be of lower frequency for a better match with the morphologically related primes. (In Experiment 1, unrelated primes were of higher frequency than the morphologically related primes, see Table 1).

As a form control, an orthographic prime condition $(\mathrm{O})$ was introduced, comprising orthographically similar words like kämmen (comb) that were neither semantically nor morphologically related to verb targets like kommen (come). Mean letter overlap was $68.1 \%$ between orthographically similar primes and corresponding verb targets, and mean percentage of shared letters (regardless of letter position) was $84.3 \%$. All but two orthographic primes were verbs.

To confirm that orthographically related primes and unrelated primes shared no meaning with the target, a semantic relatedness test was conducted including all five prime conditions. The five prime conditions of the same target were distributed across five lists according to a Latin square design. Fifty native speakers of German (who did not participate in any of the other experiments) rated the meaning relation between primes and targets on a 7-point scale from completely unrelated (1) to highly related (7).

The mean rating scores of the final set were 5.9 in the semantically related condition, 5.1 in the morphologically and semantically related condition, 2.8 in the morphologically related but semantically unrelated condition, 1.8 in the orthographic condition, and 1.4 in the unrelated condition. A one-way ANOVA was performed on mean rating scores with items $\left(F_{2}\right)$ as random 
variables. The repeated measures factor Prime Type $(-\mathrm{M}+\mathrm{S} /+\mathrm{M}+\mathrm{S} /$ $+\mathrm{M}-\mathrm{S} /$ unrelated/O) was significant, $F_{2}(4,139)=414.03, p<.0001$. Scheffé post hoc comparisons indicated that the mean rating scores of the semantically and/or morphologically related conditions differed significantly from each other as well as from the orthographic and unrelated conditions, whereas the latter two did not differ significantly from each other.

Stimulus characteristics of primes and targets are summarised in Table 3.

Filler Prime-Target Pairs. The same 180 prime-target pairs with pseudoverb targets that shared form similarity with the 36 simple verbs of the critical set were used as in Experiment 1. Corresponding to the critical set, 72 of the primes were prefixed, 108 were unprefixed verbs. An additional set of 360 filler prime-target pairs was included, 180 holding verb targets, 180 pseudoverb targets. The number of prefixed and unprefixed primes was the same as in the experimental set, 72 and 108, respectively.

Summary of the material set. The whole material set comprised 720 prime-target pairs, half with verb targets and half with pseudoverb targets. There were 180 critical prime-target pairs, of which 108 were semantically and/or morphologically related (in the $-\mathrm{M}+\mathrm{S},+\mathrm{M}+\mathrm{S},+\mathrm{M}-\mathrm{S}$ ), and 36 were form related. The 540 filler prime-target pairs comprised 216 prefixed and 324 unprefixed primes, all followed by unrelated verb targets; 72 of the prefixed and 108 of the unprefixed primes were followed by a form-related pseudoverb.

Overall, the large amount of fillers reduced (a) the critical prime-target pairs to $25 \%$ of the entire material set, (b) the overall proportion of related

TABLE 3

Stimulus characteristics of primes that were semantically related $(-M+S)$, morphologically and semantically related $(+M+S)$, morphologically related $(+M-S)$, orthographically related, or unrelated to targets in Experiment 2

\begin{tabular}{lcccc}
\hline & $\begin{array}{c}\text { Surface } \\
\text { frequency }\end{array}$ & $\begin{array}{c}\text { Lemma } \\
\text { frequency }\end{array}$ & Word length & Relatedness score \\
\hline Target kommen (come) & 98.1 & 355.2 & 6.6 & - \\
- M +S nahen (approach) & 40.2 & 143.8 & 6.7 & 5.9 \\
$+\mathrm{M}+\mathrm{S}$ mitkommen (come along) & 2.3 & 11.7 & 10.1 & 5.1 \\
$+\mathrm{M}-\mathrm{S}$ umkommen (perish) & 3.4 & 17.6 & 9.6 & 2.8 \\
Orthographic kämmen (comb) & 7.6 & 29.3 & 6.9 & 1.8 \\
Unrelated schaden (harm) & 3.0 & 15.4 & 6.6 & 1.4 \\
\hline
\end{tabular}

Note. All frequencies are from the CELEX database (Baayen et al., 1993), count is per million. 
pairs to $20 \%$ of the material, (c) the amount of prefixed primes that were followed by a related target to $25 \%$, and (d) the amount of unprefixed primes followed by a related target to $16.7 \%$.

\section{Design}

As in Experiment 1, each participant saw all 36 simple verbs in all five priming conditions. Prime-target pairs were distributed across five blocks according to the same principles as in Experiment 1. In total, the stimulus material comprised 720 prime-target pairs, presented in five experimental blocks. The starting blocks were rotated across participants. Within blocks, prime-target pairs were randomised separately for each participant. There were 20 practice trials.

\section{Procedure}

Except for the prime duration, which was manipulated as between subjects variable in Experiment 2, testing conditions were the same as in Experiment 1. In Experiment 2a, the fixation cross appeared for $1000 \mathrm{~ms}$. Then the prime appeared for $200 \mathrm{~ms}$, followed by a blank screen for $100 \mathrm{~ms}$ $(\mathrm{SOA}=300)$. In Experiment $2 \mathrm{~b}$, the fixation cross appeared for $500 \mathrm{~ms}$. Then the prime appeared for $900 \mathrm{~ms}$ and was followed by a blank screen for $100 \mathrm{~ms}$ $(\mathrm{SOA}=1000)$. In both experiments, target presentation was for $500 \mathrm{~ms}$, and the intertrial interval was $2000 \mathrm{~ms}$.

Both experiments lasted for about one hour. Participants self-administered the breaks between blocks, and were asked to take at least two breaks.

\section{Results of Experiment 2a}

Analyses were performed with participants $\left(F_{1}\right)$ and items $\left(F_{2}\right)$ treated as random variables. Only reaction times (RTs) within two standard deviations from a participant's mean were included in the data analyses. Mean response latencies were calculated for correct responses; mean error rate was $3.1 \%$. Positively correlated RT and error means over participants, $r=.27840, p<$ .0001 , indicated that there was no speed-accuracy trade-off. Mean response latencies and accuracies are summarised in Table 4, the corresponding effects are depicted in the upper panel of Figure 1.

A one-way ANOVA with the repeated measures factor Prime Type $(-\mathrm{M}+\mathrm{S} /+\mathrm{M}+\mathrm{S} /+\mathrm{M}-\mathrm{S} /$ unrelated/orthographic) was performed on $\mathrm{RT}$ and error means. The effect was significant for RT data, $F_{1}(4,96)=44.71$, $p<.0001 ; F_{2}(4,140)=53.03, p<.0001$, as well as for error data, $F_{1}(4,96)=$ $3.88, p=.0058 ; F_{2}(4,140)=4.41, p=.0022$. 
TABLE 4

Response latencies and accuracies in Experiments 2a (SOA 300) and 2b (SOA 1000)

\begin{tabular}{|c|c|c|c|c|}
\hline Prime type & $R T(S D)$ & Effect & Error $(S D)$ & Effect \\
\hline & SOA 300 & & & \\
\hline$-\mathrm{M}+\mathrm{S}$ nahen (approach) & $511(47)$ & $21 * * *$ & $0.9(1.3)$ & $(0.8)$ \\
\hline$+\mathrm{M}+\mathrm{S}$ mitkommen (come along) & $490(57)$ & $43^{* * * *}$ & $0.6(1.4)$ & $1.1^{*}$ \\
\hline + M-S umkommen (perish) & $492(60)$ & $40 * * * *$ & $0.6(1.1)$ & $1.1 *$ \\
\hline Orthographic kämmen (comb) & $548(59)$ & $-16^{* *}$ & $2.2(2.7)$ & $(-0.6)$ \\
\hline \multirow[t]{2}{*}{ Unrelated schaden (harm) } & $532(55)$ & & $1.6(2.5)$ & \\
\hline & SOA 1000 & & & \\
\hline - M+S nahen (approach) & $525(61)$ & $25 * * * *$ & $0.2(0.8)$ & $0.8^{*}$ \\
\hline$+\mathrm{M}+\mathrm{S}$ mitkommen (come along) & $493(70)$ & $57 * * * *$ & $0.2(0.7)$ & $0.8^{*}$ \\
\hline +M - S umkommen (perish) & $502(65)$ & $48^{* * * *}$ & $0.8(1.3)$ & $(0.2)$ \\
\hline Orthographic kämmen (comb) & $554(57)$ & $(-5)$ & $0.6(1.4)$ & $(0.4)$ \\
\hline Unrelated schaden (harm) & $550(63)$ & & $1.0(1.8)$ & \\
\hline
\end{tabular}

Note. Mean RTs in milliseconds (SD) and mean percentage of errors (SD) for verb targets like kommen (come) preceded by semantically related primes $(-\mathrm{M}+\mathrm{S})$, by morphologically related primes that were either semantically transparent $(+M+S)$ or semantically opaque $(+M-S)$, by orthographically similar primes, or by unrelated primes. Priming effects are calculated in contrast to the unrelated condition. Nonsignificant effects are given in parentheses, ${ }^{*} p<.05 ; * * p<.01$; *** $p<.001,{ }^{* * * *} p<.0001$ indicate significance levels for both participants and items analyses.

Planned comparisons showed that target recognition following semantically related primes was significantly faster than that after unrelated primes, $F_{1}(1,96)=15.18, p=.0002 ; F_{2}(1,140)=19.28, p<.0001$, though semantic associates did not significantly increase accuracy, $F_{1}(1,96)=2.15, p=.1458$; $F_{2}(1,140)=2.44, p=.1207$.

As in Experiment 1, morphological relatedness between primes and targets facilitated both response latencies and accuracies. Relative to unrelated verb primes, semantically transparent prefixed verbs produced significantly faster responses, $F_{1}(1,96)=62.90, p<.0001 ; F_{2}(1,140)=76.06$, $p<.0001$, and fewer errors, $F_{1}(1,96)=4.39, p=.0388 ; F_{2}(1,140)=4.98, p=$ .0273 . The same effect was found for semantically opaque prefixed verbs, which, relative to unrelated primes, yielded both significantly faster responses, $F_{1}(1,96)=55.27, p<.0001 ; F_{2}(1,140)=66.36, p<.0001$, and fewer errors, $F_{1}(1,96)=4.36, p=.0394 ; F_{2}(1,140)=4.98, p=.0273$. Replicating the findings of Experiment 1, there was no difference between the priming by semantically transparent and opaque verbs, for either response latencies or accuracies (all $F_{1}$ and $F_{2}<1$ ), indicating that morphological priming was not influenced by the semantic relation between primes and targets.

In addition, morphological relatedness yielded far more priming than semantic relatedness. Responses for verb targets following semantic 
associates were significantly slower than those following morphologically related words, regardless of whether these were semantically transparent, $F_{1}(1,96)=16.28, p<.0001 ; F_{2}(1,140)=18.75, p<.0001$, or semantically opaque, $F_{1}(1,96)=12.52, p=.0006 ; F_{2}(1,140)=14.10, p=.0003$. Although response accuracies indicated a similar pattern, it was not significant (all $F_{1}$ and $F_{2}<1$ ).

Contrary to semantic and morphological facilitation, orthographic similarity produced inhibition. Responses for targets following orthographically similar primes were significantly slower than responses following unrelated primes, $F_{1}(1,96)=8.98, p=.0035 ; F_{2}(1,140)=9.93, p=.0020$. Although response accuracies also decreased, the effect was not significant, $F_{1}(1,96)=1.10, p=.2976 ; F_{2}(1,140)=1.24, p=.2666$.

Given that orthographically related primes produced slower and more erroneous responses relative to the unrelated condition, all contrasts relative to the semantically and/or morphologically related primes were highly significant for both response latencies and response accuracies. Two of these contrasts were of particular interest. The first contrast compared pure meaning relatedness with pure form relatedness: Semantically related primes significantly facilitated responses in comparison to orthographically similar primes, as revealed by faster responses, $F_{1}(1,96)=47.50, p<.0001 ; F_{2}(1$, $140)=56.89, p<.0001$, and fewer errors, $F_{1}(1,96)=6.32, p=.0136 ; F_{2}(1$, $140)=7.17, p=.0083$.

The second contrast was between primes that show form overlap but no meaning overlap with their targets: Morphologically related but semantically opaque primes significantly facilitated responses relative to orthographically similar primes in both response latencies, $F_{1}(1,96)=108.80, p<.0001 ; F_{2}(1$, $140)=127.63, p<.0001$, and accuracies, $F_{1}(1,96)=9.83, p=.0023 ; F_{2}(1$, $140)=11.20, p=.0011$.

\section{Results of Experiment $2 b$}

Outliers were excluded and mean RTs were calculated in the same way as in Experiment 2a. Mean error rate was $1.9 \%$; one participant with a mean error rate over $11.4 \%$ was excluded from the analyses. RT and error means over participants were positively correlated, $r=.28071, p<.0001$, indicating that there was no speed-accuracy trade-off. Mean response latencies and accuracies are given in Table 4, the corresponding effects in the upper panel of Figure 1.

A one-way ANOVA with repeated measures factor Prime Type was significant for response latencies, $F_{1}(4,104)=45.16, p<.0001 ; F_{2}(4,140)=$ $56.86, p<.0001$. Regarding response accuracies, the effect was significant by participants, $F_{1}(4,104)=2.97, p=.0229$, but not by items, $F_{2}(4,140)=1.94$, $p=.1078$. 
Contrasted with unrelated primes, semantically associated primes significantly accelerated responses, $F_{1}(1,104)=18.90, p<.0001 ; F_{2}(1,140)=$ $26.97, p<.0001$, and reduced errors, $F_{1}(1,104)=7.40, p=.0077 ; F_{2}(1$, $140)=4.82, p=.0297$.

Replicating the findings of Experiments 1 and 2a, morphological relatedness yielded strong facilitation. Target recognition following semantically transparent prefixed verbs was significantly faster, $F_{1}(1,104)=96.51$, $p<.0001 ; F_{2}(1,140)=120.64, p<.0001$, and with fewer errors, $F_{1}(1,104)=$ $7.45, p=.0075 ; F_{2}(1,140)=4.82, p=.0297$, than that following unrelated primes. Most importantly, semantically opaque prefixed verbs also significantly facilitated response latencies relative to unrelated primes, $F_{1}(1,104)=$ $67.45, p<.0001 ; F_{2}(1,140)=85.83, p<.0001$, though they did not increase response accuracies $\left(F_{1}\right.$ and $\left.F_{2}<1\right)$.

Again, with regard to response latencies, semantically transparent and opaque prefixed verbs induced the same amount of priming, $F_{1}(1,104)=$ $2.60, p=.1102, F_{2}(1,140)=2.95, p=.0878$. However, response accuracies showed a weak transparency effect: responses following transparent prefixed verbs were slightly more correct than those following opaque prefixed verbs, though this difference was significant only by participants, $F_{1}(1,104)=4.19$, $p=.0432$, and not by items, $F_{2}(1,140)=2.75, p=.0996$.

As in Experiments 1 and $2 \mathrm{a}$, morphological relatedness facilitated response latencies more than semantic relatedness. Morphologically related primes, both semantically transparent primes, $F_{1}(1,104)=30.00, p<.0001$; $F_{2}(1,140)=33.52, p<.0001$, and semantically opaque primes, $F_{1}(1,104)=$ $14.94, p=.0002 ; F_{2}(1,140)=16.57, p<.0001$, significantly accelerated responses for verb targets relative to semantically associated primes. Effects of response accuracies were more complex: Semantic associates produced the same amount of errors as semantically and morphologically related primes $\left(F_{1}\right.$ and $\left.F_{2}<1\right)$, and slightly fewer errors than purely morphologically related primes, though this difference was significant only by participants, $F_{1}(1$, $104)=4.15, p=.0442 ; F_{2}(1,140)=2.75, p=.0996$.

In contrast to the findings of Experiment 2a, orthographic similarity did not inhibit target recognition. Responses for verb targets following orthographically similar primes did not significantly differ from responses following unrelated primes, either in response latencies $\left(F_{1}\right.$ and $\left.F_{2}<1\right)$, or in response accuracies, $F_{1}(1,104)=1.86, p=.1753 ; F_{2}(1,140)=1.21, p=.2741$. Nevertheless, target recognition following orthographically similar primes was significantly slower than that following either semantically related primes, $F_{1}(1,104)=26.48, p<.0001 ; F_{2}(1,140)=37.06, p<.0001$, or morphologically and semantically related primes, $F_{1}(1,104)=112.84, p<$ $.0001 ; F_{2}(1,140)=141.08, p<.0001$, or morphologically related primes, $F_{1}(1,104)=81.21, p<.0001 ; \quad F_{2}(1,140)=103.20, p<.0001$. However, orthographically similar primes induced the same amount of errors as did 
semantically related primes, $F_{1}(1,104)=1.84, p=.1784 ; F_{2}(1,140)=1.21$, $p=.2741$, morphologically and semantically related primes, $F_{1}(1,104)=$ $1.86, p=.1753 ; F_{2}(1,140)=1.21, p=.2741$, and morphologically related primes $\left(F_{1}\right.$ and $\left.F_{2}<1\right)$.

\section{Discussion of results}

The results of Experiment 2 were straightforward: First, they (almost exactly) replicate the morphological priming effects found in Experiment 1 , that is, prefixed verbs strongly facilitated the recognition of their base verbs. Moreover, both at SOA 300 and at SOA 1000, the priming by morphologically related but semantically unrelated verbs like umkommen kommen was of the same magnitude as the priming observed for semantically related verbs like mitkommen - kommen (40 ms vs. $43 \mathrm{~ms}$ at SOA 300, and 48 $\mathrm{ms}$ vs. $57 \mathrm{~ms}$ at SOA 1000, respectively). These results confirmed that morphological priming in German is not modulated by semantic transparency. The only evidence for semantic modulation arose at $1000 \mathrm{~ms}$ SOA, where transparent prefixed verbs increased the accuracy of target recognition.

Second, semantic associates like nahen - kommen produced significant priming of $21 \mathrm{~ms}$ and $25 \mathrm{~ms}$ at $300 \mathrm{~ms}$ and $1000 \mathrm{~ms}$ SOAs, respectively. Given that we used the same prime presentations (of $300 \mathrm{~ms} \mathrm{SOA}$ ) and the same semantic prime-target pairs in Experiments 1 and $2 \mathrm{a}$, we have no obvious explanation why semantic relatedness produced hardly any facilitation $(9 \mathrm{~ms})$ in Experiment 1. Whatever the reason may be, the semantic priming effects were significantly weaker, that is, almost half the size of the morphological effects found. These findings indicate that the morphological processing is more robust than the meaning processing of German prefixed verbs.

Third, the results of Experiment 2 demonstrated that morphological effects cannot be attributed to the form overlap between morphologically related primes and targets. In contrast to the morphological and semantic facilitation effects, orthographic form overlap rather hindered target recognition. At the $300 \mathrm{~ms}$ SOA, orthographically similar primes significantly inhibited the recognition of targets, though this inhibition did not reach significance at the $1000 \mathrm{~ms}$ SOA. This pattern may indicate that the inhibitory influence of form similarity becomes weaker the longer the prime is consciously perceived.

Two contrasts were of particular interest: First, the comparison between the semantic and orthographic priming conditions allowed us to disentangle effects of meaning similarity from those of form similarity. Indeed, this contrast indicated that meaning relation between primes and targets facilitates processing, even without form overlap. 
The second contrast measured whether morphological priming differs from orthographic priming. For this purpose, prime-target pairs that share form overlap but do not share overt meaning were compared, that is, orthographically related (and semantically unrelated) pairs like kämmen kommen and morphologically related but semantically unrelated pairs like umkommen - kommen. Morphologically related primes produced strong facilitation in comparison to the orthographically related primes. Since both types of prime-target pairs are form related but not meaning related (as the ratings of the semantic association test confirmed), the assumption that whole words are processed as whole units cannot sufficiently explain the results. The facilitation by morphologically related pairs rather points towards the morphemic constituents as processing units, which, by definition, map form units to meaning units. Most importantly, these morphemic form-to-meaning mappings are independent of the form and meaning relations of the larger word unit to which they belong.

To summarise, Experiment 2 replicated the findings of Experiment 1 that morphological priming was not (Exp. 2a) or hardly (Exp. 2b) modulated by semantic transparency. Furthermore, form similarity without morphological relatedness did not produce facilitatory effects. These findings argue against the possibility that morphological priming effects are due to surface form overlap between primes and targets.

\section{Post-hoc analyses}

One could argue that repetition effects may have affected the priming patterns: Participants saw the same target five times (each with a different prime in a different block), so that the first presentation of a target may lay down a memory trace of that episode (including the response), which is activated together with the lexical record by the second presentation of the target, thus creating a repetition effect.

To control for repetition effects, prime-target pairs were randomised in each block, and a high proportion of filler prime-target pairs was inserted (see Methods sections for details). Nevertheless, to dispel all doubts, the following post-hoc analyses were conducted on the presentations of the first block only, when repetition could not have affected the results. As the lower panel of Figure 1 indicates, the priming effects of the first block presentations overall replicate those of the analyses including all blocks.

For each experiment separately, a one-way ANOVA with the repeated measures factor Prime Type was performed on latency and accuracy measures. In Experiment 1, the presentation of blocks was not randomised, so that only the analyses by participants will be reported. Like in the analyses comprising all blocks, the effect of Prime Type was significant for RT data, $F_{1}(4,104)=5.75, p=.0003$, but not for error data $\left(F_{1}<1\right)$. Also, planned 
comparisons on the RT data replicated the previous findings that pure semantically related primes did not facilitate target recognition relative to the unrelated condition $\left(F_{1}<1\right)$, whereas both semantically transparent prefixed verbs, $F_{1}(1,104)=6.91, p=.0099$, and semantically opaque prefixed verbs, $F_{1}(1,104)=13.93, p=.0003$, did. Most importantly, there was no difference between the two morphologically related conditions, $F_{1}(1,104)=1.22, p=$ .2725. Also identity primes significantly facilitated target recognition, $F_{1}(1$, $104)=6.52, p=.0121$, however, in contrast to the analyses calculated for all blocks, verb targets were facilitated to the same extent by themselves as they were by both semantically transparent $\left(F_{1}<1\right)$ and semantically opaque prefixed verbs, $F_{1}(1,104)=1.39, p=.2408$.

In Experiment $2 \mathrm{a}$, the effect of Prime Type was significant for both RT data, $F_{1}(4,96)=7.59, p<.0001 ; F_{2}(4,140)=3.66, p=.0073$, and error data, $F_{1}(4,96)=3.17, p=.0171 ; F_{2}(4,140)=4.08, p=.0037$. Although purely semantically associated primes did not accelerate target recognition, $F_{1}(1$, $96)=2.53, p=.1152 ; F_{2}(1,140)=2.64, p=.1063$, they increased the accuracy of target recognition, $F_{1}(1,96)=5.90, p=.0170 ; F_{2}(1,140)=$ $8.58, p=.0040$. The trend to inhibition by orthographic controls did not reach significance, neither for latencies, $F_{1}(1,96)=1.57, p=.2137 ; F_{2}<1$, nor for accuracies, $F_{1}(1,96)=1.02, p=.3158 ; F_{2}(1,140)=2.55, p=.1124$. As in the analyses with all blocks, both types of morphological derivations significantly facilitated target recognition relative to the unrelated condition: Semantically transparent prefixed verbs facilitated both response latencies, $F_{1}(1,96)=9.94, p=.0022 ; F_{2}(1,140)=6.80, p=.0101$, and response accuracies, $F_{1}(1,96)=8.08, p=.0055 ; F_{2}(1,140)=11.37, p=.0010$. Also semantically opaque prefixed verbs accelerated latencies, $F_{1}(1,96)=10.00$, $p=.0021 ; F_{2}(1,140)=6.85, p=.0098$, and increased accuracies, $F_{1}(1,96)=$ $7.82, p=.0062 ; F_{2}(1,140)=10.40, p=.0016$. Most importantly, semantically opaque and transparent primes produced the same amount of facilitation, both for response latencies and accuracies (all $F_{1}$ and $F_{2}<1$ ).

In Experiment $2 b$, the effect of Prime Type was significant for RT data, $F_{1}(4,104)=7.29, p<.0001 ; F_{2}(4,140)=4.31, p=.0025$, but not for error data $\left(F_{1}\right.$ and $\left.F_{2}<1\right)$. As in the analyses comprising all blocks, planned comparisons on the RT data indicated that the orthographic inhibition was not significant $\left(F_{1}\right.$ and $\left.F_{2}<1\right)$. Semantically associated primes induced significant facilitation, $F_{1}(1,104)=7.62, p=.0068 ; F_{2}(1,140)=6.41, p=$ .0124 , and to the same degree as did morphologically related primes (all $F_{1}$ and $\left.F_{2}<1\right)$. As in all other analyses, both semantically transparent primes, $F_{1}(1,104)=11.48, p=.0010 ; F_{2}(1,140)=8.43, p=.0043$, and semantically opaque primes, $F_{1}(1,104)=6.20, p=.0144 ; F_{2}(1,140)=4.21$, $p=.0421$, facilitated response latencies, but without any transparency effect between them (all $F_{1}$ and $F_{2}<1$ ). 
On the whole, the post-hoc analyses on first block presentations replicated the findings of the overall analyses: strong morphological facilitation that is (a) not modulated by semantic transparency, (b) stronger than semantic facilitation (at SOA 300), and (c) different from orthographic (nonsignificant) inhibition.

A comparison of the priming patterns across the overall analyses and the first block analyses reveals that the repetition of the targets modified the result patterns in two respects: In Experiment 1, the repetition of the target (in the overall analyses) enlarged identity priming, so that it was stronger than the priming of the semantically transparent and opaque conditions, whereas identity priming was equivalent to transparent and opaque priming when participants saw a target for the first time.

Second, in Experiment 2b (at SOA 1000), the repetition of the target (in the overall analyses) enhanced the morphological effects relative to the semantic effects, whereas morphological and semantic priming effects were equivalent when participants saw the target for the first time. Since the repetition of the target altered the pattern of results in these ways, only the findings of the first block analyses will be discussed below.

\section{GENERAL DISCUSSION}

The aim of the present study was to investigate whether morphological processing is modulated by semantic transparency. For this purpose, we used German prefixed verbs, since they provide the opportunity to manipulate the amount of meaning relatedness to the same base verb. The results were clearcut: Morphological priming effects were independent of semantic transparency. Semantically opaque prefixed verbs like umkommen (perish) primed their base verbs like kommen (come) to the same extent as did semantically transparent prefixed verbs like mitkommen (come along). These morphological priming effects were extremely robust, since they were replicated in three experiments using different SOA manipulations (300 $\mathrm{ms}$ in Experiments 1 and 2a, $1000 \mathrm{~ms}$ in Experiment 2b). The effects were highly significant in reaction times as well as in the error data, both in the firstblock analyses and in the overall analyses.

Our findings of opaque morphological facilitation corroborate the findings of a recent study on German prefix verbs with ver- (Schirmeier, Derwing, \& Libben, 2005). Prefix verbs like verdauen (digest) were rated as not comprising the meaning of their bound (and thus meaningless) stems like dauen. Nevertheless, under visual prime presentations at $100 \mathrm{~ms}$ SOA, these bound stems primed their corresponding prefix verbs to the same degree as did transparently related stems. 
Overall, findings in German seem to differ from those in other IndoEuropean languages, where morphological effects have emerged only between semantically related prime-target pairs, once participants were aware of the prime: under visual priming at long SOAs in English (e.g., Feldman et al., 2004; Rastle et al., 2000), as well as under cross-modal priming conditions in English (Marlsen-Wilson, Tyler, Waksler, \& Older, 1994), French (Longtin et al., 2003), and Polish (Reid \& Marslen-Wilson, 2000). In Serbian, under visual prime presentations at $250 \mathrm{~ms}$ SOA, semantically opaque primes yielded significant morphological priming, but only if primes and targets were presented in alternating (Cyrillic and Roman) scripts, and not if they were presented in the same script (Feldman, BaracCikoja, \& Kostic, 2002). ${ }^{3}$

One could argue that the strong morphological effects in our study emerged due to expectancy: With long SOA presentations, participants are consciously aware of the prime and may come to expect certain relations between prime and target, such as the morphological relation. However, the same argument should apply to all other overt priming studies (cited above) as well, where the possible awareness of prime-target relations did not yield any priming by semantically opaque derivations. Furthermore, to avoid expectancy effects, we inserted large numbers of fillers that reduced the overall proportion of related prime-target pairs to $12 \%$ and $20 \%$ in Experiments 1 and 2, respectively (for more detailed relatedness proportions see the Methods sections). These relatedness proportions are similar or even smaller than those used in other overt priming studies where semantically opaque pairs did not yield priming (e.g., relatedness proportion of $15 \%$ in Feldman et al., 2004; 25\% in Longtin et al., 2003; 25\% in Marslen-Wilson et al., 1994; 17\% in Rastle et al., 2000). Hence, the expectation of a particular prime-target relation cannot be the main reason for the semantically opaque priming effects in the present study. Thus, we may conclude that the strong morphological effects independent of semantic relatedness in German are genuine.

To measure whether the morphological priming effects were 'full' or 'partial', Experiment 1 contrasted the morphologically related conditions with an identity condition. The analyses of the first block showed that both the semantically transparent and the semantically opaque morphological conditions produced the same amount of priming as did the identity condition (see also the lower panel of Figure 1). 'Full' priming of morphologically related prefixed verbs, and in particular 'full' priming

\footnotetext{
${ }^{3}$ It is possible that the application of different scripts reduced the orthographic inhibition usually found under these SOA conditions due to a decrease in the form overlap between primes and targets. Morphological effects could thus emerge for semantically opaque derivations.
} 
without meaning relatedness by semantically opaque primes, provides strong evidence that the stem of the derived form was accessed and activated.

Thus, our findings demonstrate that morphological processing is independent of meaning relatedness. To measure the effect of pure meaning relatedness, we inserted a condition in which primes and targets were semantically but not morphologically related, such as nahen - kommen (approach - come). In contrast to the strong morphological effects, semantic facilitation did not unequivocally occur across the experiments and was significantly weaker than morphological facilitation at SOA 300 (Experiments 1 and 2a). Semantic priming reached the same strength as morphological priming only at SOA 1000 (Experiment 2b; indicated by the analyses of the first block, see also lower panel of Figure 1). This indicates that, in German, morphological relatedness is relatively stronger and builds up faster than semantic relatedness.

Using similar experimental conditions, previous reports on semantic priming effects in German have produced inconsistent results, either failing to find significant facilitation between purely semantically associated verbs (Zwitserlood, Drews, Bolwiender, \& Neuwinger, 1996) or reporting only weak effects (of $15 \mathrm{~ms}$; Drews et al., 2000). Nevertheless, the semantic priming effects of Experiment 2 certainly correspond to the findings of semantic facilitation in other languages such as English (Feldman, 2000; Rastle et al., 2000; Raveh, 2002) and Dutch (Zwitserlood et al., 1996). Experimental conditions in which primes are consciously perceived are supposed to increase semantic effects (see e.g., Feldman et al., 2004; Feldman \& Prostko, 2002; Raveh \& Rueck1, 2000). Hence, the present findings of strong morphological priming that is unaffected by semantic transparency stress the robustness of the morphological effects even more.

Experiment 2 confirmed that the morphological effects cannot be attributed to mere form overlap between primes and targets. Orthographically similar primes like kämmen (comb) (significantly or insignificantly) inhibited the recognition of a target like kommen (come). These results concur with earlier findings in Indo-European languages, according to which the orthographic similarity of clearly visible primes (at long SOAs of $230 \mathrm{~ms}$ or more) hinders target recognition. Such orthographic inhibition was found in languages like English (Feldman, 2000; Pastizzo \& Feldman, 2002; Rastle et al., 2000), Dutch (Drews \& Zwitserlood, 1995; Segui \& Grainger, 1990), German (Drews \& Zwitserlood, 1995), as well as in French (Grainger, 1990; Segui \& Grainger, 1990), and Serbian (Feldman \& Andjelkovic, 1992).

To summarise, our findings demonstrate that morphological effects in German are particularly robust even when primes and targets share no transparent meaning. Furthermore, the effects tend to be stronger than pure semantic effects and cannot be reduced to pure form effects. 
Morphological effects independent of semantic transparency have also been found in English and French, though only under masked priming conditions. Words of apparent morphological complexity like number (-er occurs as suffix in other English words) facilitated the recognition of stems like numb, whereas words like brothel that did not comprise a suffix-like ending did not facilitate the recognition of broth (Longtin et al., 2003; Rastle et al., 2000, 2004). These findings were interpreted to indicate that in early visual word recognition, morphological segmentation operates on a purely orthographic basis - not only independent of semantic relatedness but also independent of morphological relatedness. Yet, this segmentation process ceases to affect the word recognition process as soon as the morphemic constituents are semantically integrated (when primes are consciously perceived).

In the present study, semantic integration (under overt priming conditions) did not override morphological effects. Hence, the question arises why morphological priming effects in German contrast with the established findings in English, French, and other Indo-European languages. A comparison across languages on whether or not morphological priming effects withstand semantic integration depicts a continuum with two endpoints: Mandarin Chinese without morphological effects due to its lack of derivational morphology may represent one extreme (e.g., MarslenWilson, 2001; Taft \& Zhu, 1995), and Arabic showing the strongest morphological effects the other extreme. Indo-European languages seem to be distributed in between these two endpoints, with no apparent correlation between particular language families, such as Germanic, Romance, or Slavic languages, and the strength of morphological priming effects. Languages like English, French, Polish, and Bulgarian show morphological priming effects under the precondition of semantic transparency, whereas Serbian and Dutch may - under certain circumstances - show morphological priming effects of semantically opaque derivations. Similarly, Hebrew shows semantic transparency effects and priming effects of semantically opaque words only if facilitation is measured relative to an orthographic (and thus slightly inhibiting) control but not relative to the unrelated control condition (Frost et al., 2000). In this respect, German, with its strong morphological effects regardless of semantic transparency falls closest to the endpoint represented by Arabic.

\section{LANGUAGE LINEARITY VERSUS MORPHOLOGICAL RICHNESS}

As long as research on morphological priming effects was reduced to the contrast between English and Hebrew, both language linearity and 
morphological richness provided possible explanations for the salience of morphological processing in one type of language but not in the other.

'The likely contrast between English and Hebrew is not just in the extent and the richness of a language's morphological system, but also in the degree to which morphological combination and analysis is an obligatory part of the representation and processing of words in the language - both at the level of underlying lexical entries and as phonologically realized surface forms' (Frost et al., 2000, p. 1286). That is, not only the structure of the morphemes but also their 'phonological entity' may play a role: in a concatenative language like English, words and morphemes are fully specified phonological units. In nonconcatenative languages like Hebrew and Arabic, the root and word pattern are interwoven, so that neither of these units represents a pronounceable phonological unit, and neither the root nor the word pattern can be pronounced one without the other.

Take as an example the Hebrew letter cluster $n v x l$ that can take the meaning nuxal ('we will be able to') or noxel ('swindler'). The phonological and meaning ambiguity can be solved without any need of morphological decomposition: $n v x l$ as a whole word corresponds to two phonological representations and two meanings, and the semantic context indicates the correct meaning and pronunciation. Another possibility may be that a native speaker needs to extract the root in order to know which word pattern and hence which pronunciation to apply. In the case of $n v x l$, whether the root (j) $x l$ or $n x l$ is extracted determines whether the word pattern $n u \_a \_$or $\_o \_e$, respectively, is to be assigned. ${ }^{4}$ Indeed, there is abundant evidence that native speakers automatically parse a word into its non-linear morphemic constituents (e.g., Boudelaa \& Marslen-Wilson, 2004b, 2005; Frost et al., 1997, 2000). We thus propose that the discrimination between root and word pattern is a prerequisite for the pronounceability of the whole word. In this respect, the linearity of the language together with the phonological entity of a morpheme may shape the decomposition process in visual word recognition: If words or morphemes possess a phonological entity, as is the case in concatenative languages like English and French, morphemic decomposition is optional. If, however, morphemic constituents do not possess a phonological entity, as is the case in nonconcatenative languages like Hebrew and Arabic, morphological decomposition becomes an essential process. The automatic reference to the root will always activate its base meaning, which may account for the lack of semantic transparency effects in Semitic languages.

\footnotetext{
${ }^{4}$ The letter $v$ ('vav') in $n v x l$ may represent the vowels $/ \mathrm{u} /$ or $/ \mathrm{o} /$; the verbal root $j x l$ is a 'defective' root (see e.g. Velan, Frost, Deutsch, \& Plaut, 2005) that surfaces in some verb patterns as $x l$.
} 
However, findings on morphological processing across languages, as represented by the continuum described above do not directly correspond to the contrast between linear Indo-European versus nonlinear Semitic languages, as the weak priming effects of semantically opaque words in Hebrew and the strong priming effects of opaque derivations in German demonstrate. Indeed, linearity seems to be a graded rather than a clear-cut language characteristic. For example, recent research has shown that there is a tendency to linear word formation observable in Modern Hebrew, as the rate of the root-and-word-pattern formation decreases and the rate of linear stem-and-suffix formations and compounding rises (Schwarzwald, 2003).

On the other hand, Indo-European languages also show non-linear word formation processes like infixations that make the lexical root discontinuous and thus less transparent. German makes abundant use of infixes in form of Ablaut and Umlaut in the formation of verb inflections like laufen - läuft (run - runs), noun plurals like Ofen - Öfen (oven - ovens) or Buch - Bücher (book - books), diminutives like Haus - Häuschen (house - little house), and derivations like Kamm - kämmen (comb, n. - comb, v.). ${ }^{5}$

The existence of phonological entities for linear morphemes versus the lack of phonological entities for nonlinear morphemes may explain the existence of semantic transparency effects or the lack thereof in those languages that are strictly linear or nonlinear, such as English and Arabic, respectively. Languages such as German and Hebrew seem to attenuate this strict distinction: German is in principal linear but possesses some nonlinear characteristics, and Hebrew is in principal nonlinear but also possesses some linear characteristics. In any case, further research is required to determine the exact nature of how language linearity relates to semantic transparency effects.

An alternative explanation to linearity has been offered by distributed connectionist approaches suggesting that the occurrence of semantic transparency effects is determined by the morphological richness of a language (Plaut \& Gonnerman, 2000; Raveh \& Rueckl, 2000; Rueckl et al., 1997). Since morphological regularities emerge as the result of statistical regularities between form and meaning overlap, these regularities determine the performance of the system: the more morphological regularities (i.e., form and meaning overlap), the faster and more efficient the system may operate. Hence, in a system with abundant morphological regularities, these regularities will guide visual word recognition (Rueckl \& Raveh, 1999). Indeed, when a network model experienced a morphologically impoverished

\footnotetext{
${ }^{5}$ The Umlaut in German is represented by the graphemes $\ddot{\theta}, \ddot{o}$, and $\ddot{u}$. These graphemes represent different phonemes than those represented by the graphemes $a$, $o$, and $u$, as the minimal pairs Bar (bar) - Bär (bear), losen (draw lots) - lösen (dissolve), and lugen (peek) - lügen (lie) show.
} 
environment (simulating a language like English), in which mappings between orthographic surface forms and their meanings are mostly idiosyncratic, morphological regularities played a minor role (Plaut \& Gonnerman, 2000). In contrast, in a morphologically rich environment (simulating languages like Hebrew), where the mappings between orthographic form and meaning are straightforward, morphological regularities dominated language processing and simulated morphological priming effects that were independent of semantic relatedness.

As long as research on morphological priming effects concentrated on the comparison between Hebrew and English, it was convenient to agree with the contrast of morphologically rich versus impoverished languages. However, recent studies in French, Polish, Bulgarian, and other Indo-European languages show effects of semantic transparency that are similar to those in English, in spite of the fact that these languages all possess 'richer' morphological systems than English. In contrast, the morphologically rich language German shows morphological effects regardless of semantic transparency. This raises several questions: First, in what way is German morphologically richer than other Indo-European languages, that is, how do we define 'morphological richness'? Second, what are the specific morphological characteristics that determine whether semantic transparency plays or does not play a role in language perception?

Differences in morphological richness between Germanic languages such as English, Dutch, and German may derive from typological differences that emerged during the language history. In Germanic languages, a drift from synthetic ('morphologically rich') to analytic ('morphologically impoverished') language construction can be observed (Roelcke, 1997): From ProtoGermanic, where grammatical relations were dominantly marked by morphology, a tendency evolved to reduce morphological markedness and convey grammatical relations by syntax, for example by a stricter word order (De Vogelaer, 2007). In this sense, German represents the most conservative language among Germanic languages, keeping morphological markers to indicate grammatical functions, whereas English is the most innovative language that has developed syntactic markers for expressing grammatical functions.

Nevertheless, the question remains of which particular language characteristics determine the strength of morphological priming effects. Is it the complexity of the inflectional system, the derivational system, the productivity of compounding, the overall proportion of complex versus simplex words or the overall proportion of semantically transparent versus opaque words in a given language that determines semantic transparency effects?

Given that neither linguistic nor psycholinguistic research has dealt with these questions so far, we dare to offer a mere guess. Since several languages like French and Polish possess rich inflectional systems as well as abundant 
derivations, it may be the compound system that differs across languages. In German, the creation of new compounds is very productive, so that the native speaker may be tuned to perceive the constituent morphemes of a new word. For example, traffic news on the radio may report that a Steinewerfer (someone who throws stones) is hindering traffic on the highway, assuming that native speakers can 'put the pieces together', in spite of the fact that the derivation Werfer (someone who throws) from the verb werfen (throw) is hardly ever used on its own and there is no verb like steinewerfen (throw stones).

In any case, systematic research is required to be able to link linguistic typologies to the corresponding psycholinguistic perception of morphology. However, any categorical distinction may be too simple: obviously, both linearity and morphological richness are graded language characteristics. Likewise, semantic transparency is not a binary feature, and morphological priming effects have been shown to vary according to the gradual overlap of form and meaning between word pairs (Gonnerman et al., 2000). Thus, a model should be able to handle various graded language features as well as the processing of both semantically transparent and opaque derivations.

\section{A SINGLE SYSTEM MODEL}

We propose such a single system by adapting a model that was first introduced to account for the processing of regular and irregular inflection in

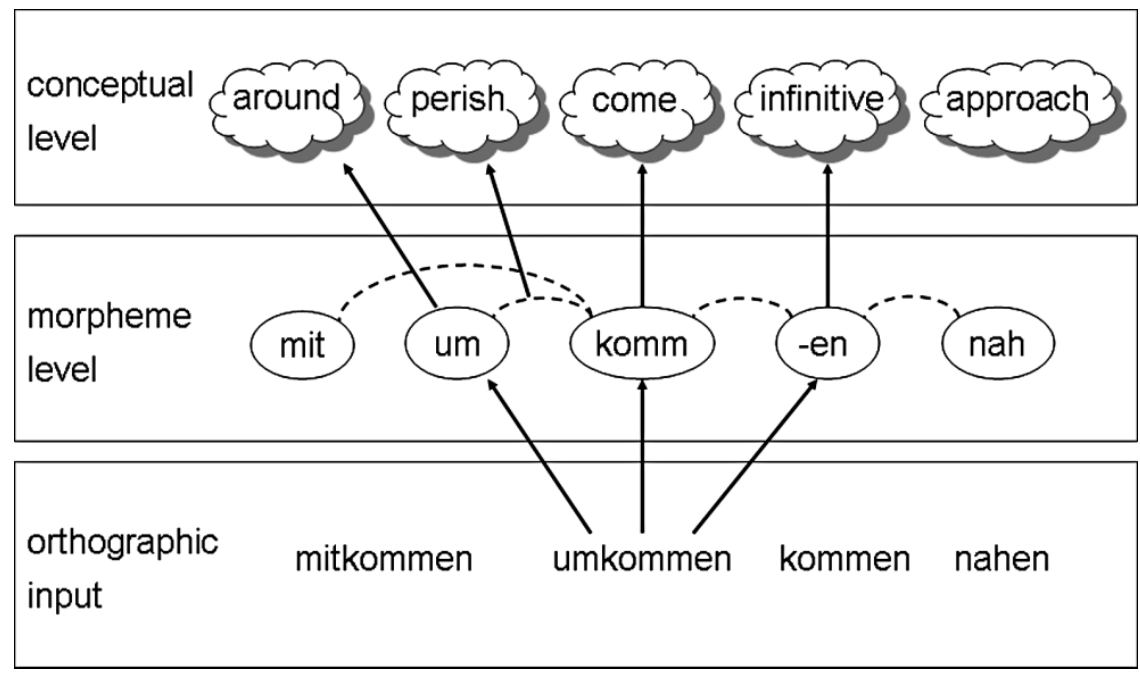

Figure 2. A single system model as applied to the processing of both semantically transparent and semantically opaque derivations. (See text for further details.) 
German (Smolka, Zwitserlood, \& Rösler, 2007). The model is depicted in Figure 2. Basically, the model's primary purpose is to map orthographic codes onto meaning codes. Orthographic strings like mitkommen (come along) and umkommen (perish) are segmented into their constituent morphemes: mit-, um-, komm, -en. This initial process comprises reiterative orthographic segmentation, which maps form to meaning. The products of this orthographic segmentation process are the smallest meaningful units, namely, morphemic constituents.

Connectionist models assume that these morphological regularities are represented indirectly in the hidden layers between orthographic and semantic codes (Plaut \& Gonnerman, 2000; Raveh, 2002; Rueck1 \& Raveh, 1999). However, two findings of the present study indicate that morphemic representations take psycholinguistic reality beyond form and meaning overlap: First, morphological priming effects were not only independent of semantic relatedness but also far stronger than semantic effects, and second, morphological effects were facilitatory at the same time as orthographic effects were inhibitory. We thus prefer to think in terms of explicit morphological representations.

Irrespective of whether morphological regularities should be represented in a distributed or explicit way, the meaning of these morphemes is accessed and activates the underlying concepts at the conceptual level: along, around, come, and infinitive, respectively. Thus, both the morpheme komm and its related concept come are activated to the same degree by the derived verbs mitkommen (transparent) and umkommen (opaque), independently of their semantic transparency. This activation facilitates the recognition of the target kommen (come) that activates the same units both at the morpheme level, komm, and at the conceptual level, come. Indeed, the finding that semantically opaque verbs produced the same amount of facilitation as identical primes is the strongest evidence for stem access. Such 'full' priming allows us to assume the same system for the processing of semantically transparent and opaque forms. Furthermore, such 'full' priming indicates that the stems were accessed before the meaning of the whole word, which contradicts the assumptions of a supralexical model as suggested by Giraudo and Grainger (2000).

In contrast to a morphologically related prime, a semantically related but morphologically unrelated word like nahen (approach) activates a different constituent at the morpheme level, nah, and consequently a different concept (approach) at the conceptual level. Only spreading of activation at the conceptual level from the concept approach to semantically related concepts, such as come, can facilitate the recognition of the target verb come. This spread of activation is weaker than the activation produced by a morphologically related word. Indeed, we found only 'partial' priming for semantically related verbs. Thus, the model outlined in 
Figure 2 can account for the finding of the present study, that the activation of morphologically related words is stronger - independent of their semantic transparency - than the activation of semantically related but morphologically unrelated words.

The joint activation of a concept by morphemic constituents suffices to derive the concept of a semantically transparent word. Semantically opaque words require the activation of a separate concept, represented by the link between the morphemic constituents. Thus, the link between the particular stem-affix combination komm (come) and um (around) will activate the concept perish, which differs from the concepts of its constituents come and around. The strength of the link reflects the whole word and its surface frequency. It differs from the stem or affix frequency of the morphemic constituents. Hence, morphemic constituents and whole words, as well as their stem and surface frequencies, respectively, are represented and accessed at the same level. This makes the requirement for assuming two different processing stages - early stem access and later whole word access - as assumed by Taft (2003; 2004; Taft \& Kougious, 2004), unnecessary.

In the present model, the activation strength of the constituents in relation to that of the links between these constituents will determine which of the concepts will be more strongly activated: the concepts relating to the individual morphemes or those of the morpheme combination, that is, the opaque meaning.

Cross-language differences can be explained by differences in the relative weighting that the sublevels receive. In a morphologically rich language, such as German and Arabic, the morphemic constituents predominate the meaning: a morpheme immediately activates its underlying concept, independent of the affix or word pattern relations. In a morphologically impoverished language like English, the activation of the single constituents of a complex word receives less weight than the links between the constituents (corresponding to word units), so that the activation via the combined constituents outweighs that of the single constituents. In the case of a transparent word, the morphemic constituents and the connections between them will feed the same concept. In the case of a semantically opaque word, different concepts will be activated, and the activation of the concept that is fed by the joint connections will surpass the activation of the concept fed by the single constituent.

The present model resembles other recent models (e.g., Longtin et al., 2003; Rastle et al., 2000, 2004) that assume automatic morphemic decomposition in early visual word recognition. However, in accordance with the findings in English and French, these models assume that morphological effects represent subprocesses of orthographic segmentation that vanish under overt priming conditions as soon as semantic meaning relations become apparent. In addition to these early effects, the present 
model can also explain the resilient morphological effects under overt priming conditions in German.

To summarise, the model outlined in Figure 2 presents a single system that processes semantically transparent and semantically opaque words. Moreover, it presumes the same mechanisms for morphologically rich and impoverished languages. The difference between languages is in the relative weighting that the sublevels receive.

Manuscript received October 2007 Revised manuscript received March 2008 First published online May 2008

\section{REFERENCES}

Baayen, R., Piepenbrock, R., \& van Rijn, H. (1993). The CELEX lexical database (on CD-ROM). Philadelphia, PA: Linguistic Data Consortium, University of Pennsylvania.

Bentin, S., \& Feldman, L. B. (1990). The contribution of morphological and semantic relatedness to repetition priming at short and long lags: Evidence from Hebrew. Quarterly Journal of Experimental Psychology, 42, 693-711.

Boudelaa, S., \& Marslen-Wilson, W. D. (2000). Non-concatenative morphemes in language processing: Evidence from Modern Standard Arabic. Proceedings of the Workshop on Spoken Word Access Processes, 1, 23-26. Nijmegen, Netherlands.

Boudelaa, S., \& Marslen-Wilson, W. D. (2001). Morphological units in the Arabic mental lexicon. Cognition, 81, 65-92.

Boudelaa, S., \& Marslen-Wilson, W. D. (2004a). Abstract morphemes and lexical representation: The CV-Skeleton in Arabic. Cognition, 92, 271-303.

Boudelaa, S., \& Marslen-Wilson, W. D. (2004b). Allomorphic variation in Arabic: Implications for lexical processing and representation. Brain and Language, 90, 106-116.

Boudelaa, S., \& Marslen-Wilson, W. D. (2005). Discontinuous morphology in time: Incremental masked priming in Arabic. Language and Cognitive Processes, 20, 207-260.

Deutsch, A., Frost, R., \& Forster, K. I. (1998). Verbs and nouns are organized and accessed differently in the mental lexicon: Evidence from Hebrew. Journal of Experimental Psychology: Learning, Memory, and Cognition, 24, 1238-1255.

De Vogelaer, G. (2007). Extending Hawkins' comparative typology: Case, word order, and verb agreement in the Germanic languages. Nordlyd, 34, 167-182.

Drews, E., \& Zwitserlood, P. (1995). Morphological and orthographic similarity in visual word recognition. Journal of Experimental Psychology: Human Perception and Performance, 21, 10981116.

Drews, E., Zwitserlood, P., \& Neuwinger, E. (2000). How semantic is morphological priming? Evidence from derivationally prefixed verbs in German. Unpublished manuscript.

Duden (2003). Deutsches Universalwörterbuch. 5. Auflage, Mannheim: Dudenverlag.

Feldman, L. B. (2000). Are morphological effects distinguishable from the effects of shared meaning and shared form? Journal of Experimental Psychology: Learning, Memory, and Cognition, 26, 1431-1444.

Feldman, L. B., \& Andjelkovic, D. (1992). Morphological analysis in word recognition. In R. Frost \& L. Katz (Eds.), Orthography, phonology, morphology, and meaning (pp. 343-360). Amsterdam: North Holland. 
Feldman, L. B., Barac-Cikoja, D., \& Kostic, A. (2002). Semantic aspects of morphological processing: Transparency effects in Serbian. Memory and Cognition, 30, 629-636.

Feldman, L. B., \& Larabee, J. (2001). Morphological facilitation following prefixed but not suffixed primes: Lexical architecture or modality-specific processes? Journal of Experimental Psychology: Human Perception and Performance, 27, 680-691.

Feldman, L. B., \& Prostko, B. (2002). Graded aspects of morphological processing: Task and processing time. Brain and Language, 81, 12-27.

Feldman, L. B., \& Soltano, E. G. (1999). Morphological priming: The role of prime duration, semantic transparency, and affix position. Brain and Language, 68, 33-39.

Feldman, L. B., Soltano, E. G., Pastizzo, M. J., \& Francis, S. E. (2004). What do graded effects of semantic transparency reveal about morphological processing? Brain and Language, 90, 17-30.

Fowler, C. A., Napps, S. E., \& Feldman, L. (1985). Relations among regular and irregular morphologically related words in the lexicon as revealed by repetition priming. Memory and Cognition, 13, 241-255.

Frost, R., Deutsch, A., Gilboa, O., Tannenbaum, M., \& Marslen-Wilson, W. (2000). Morphological priming: Dissociation of phonological, semantic, and morphological factors. Memory and Cognition, 28, 1277-1288.

Frost, R., Forster, K. I., \& Deutsch, A. (1997). What can we learn from the morphology of Hebrew? A masked-priming investigation of morphological representation. Journal of Experimental Psychology: Learning, Memory, and Cognition, 23, 829-856.

Giraudo, H., \& Grainger, J. (2000). Effects of prime word frequency and cumulative root frequency in masked morphological priming. Language and Cognitive Processes, 15, 421-444.

Gonnerman, L. M., Seidenberg, M. S., \& Andersen, E. S. (2000). Graded semantic and phonological similarity effects in priming: Evidence for a distributed connectionist approach to morphology. Unpublished manuscript.

Grainger, J. (1990). Word frequency and neighborhood frequency effects in lexical decision and naming. Journal of Memory and Language, 29, 228-244.

Grainger, J., Colé, P., \& Segui, J. (1991). Masked morphological priming in visual word recognition. Journal of Memory and Language, 30, 370-384.

Longtin, C., Segui, J., \& Hallé, P. A. (2003). Morphological priming without morphological relationship. Language and Cognitive Processes, 18, 313-334.

Marslen-Wilson, W. (2001). Access to lexical representations: Cross-linguistic issues. Language and Cognitive Processes, 16, 699-708.

Marslen-Wilson, W., Tyler, L. K., Waksler, R., \& Older, L. (1994). Morphology and meaning in the English mental lexicon. Psychological Review, 101, 3-33.

Meunier, F., \& Segui, J. (2002). Cross-modal priming in French. Brain and Language, 81, 89-102.

Napps, S. E. (1989). Morphemic relationships in the lexicon: Are they distinct from semantic and formal relationships? Memory and Cognition, 17, 729-739.

Napps, S. E., \& Fowler, C. A. (1987). Formal relationships among words and the organization of the mental lexicon. Journal of Psycholinguistic Research, 16, 257-272.

Olsen, S. (1996). Partikelverben im Deutsch-Englischen Vergleich [Particle verbs in a comparison of German and English]. In E. Lang \& G. Zifonum (Eds.), Deutsch-typologisch (pp. 261-288). Berlin: De Gruyter.

Pastizzo, M. J., \& Feldman, L. B. (2002). Discrepancies between orthographic and unrelated baselines in masked priming undermine a decompositional account of morphological facilitation. Journal of Experimental Psychology: Learning, Memory, and Cognition, 28, 244 249.

Plaut, D. C., \& Gonnerman, L. M. (2000). Are non-semantic morphological effects incompatible with a distributed connectionist approach to lexical processing? Language and Cognitive Processes, 15, 445-485. 
Rastle, K., Davis, M. H., Marslen-Wilson, W. D., \& Tyler, L. K. (2000). Morphological and semantic effects in visual word recognition: A time-course study. Language and Cognitive Processes, 15, 507-537.

Rastle, K., Davis, M. H., \& New, B. (2004). The broth in my brother's brothel: Morphoorthographic segmentation in visual word recognition. Psychonomic Bulletin and Review, 11, 1090-1098.

Raveh, M. (2002). The contribution of frequency and semantic similarity to morphological processing. Brain and Language, 81, 312-325.

Raveh, M., \& Rueckl, J. (2000). Equivalent effects of inflected and derived primes: Long-term morphological priming in fragment completion and lexical decision. Journal of Memory and Language, 42, 103-119.

Reid, A., \& Marslen-Wilson (2000). Organising principles in lexical representation: Evidence from Polish. In L. R. Gleitman, \& A. K. Joshi (Eds.), Proceedings of the Twenty-Second Annual Conference of the Cognitive Science Society (pp. 387-392). Mahwah, NJ: Lawrence Erlbaum Associates.

Roelcke, T. (1997). Sprachtypologie des Deutschen: historische, regionale und funktionale Variation [Language typology of German: historical, regional, and functional variation]. Berlin: de Gruyter.

Rueckl, J. G., \& Raveh, M. (1999). The influence of morphological regularities on the dynamics of a connectionist network. Brain and Language, 68, 110-117.

Rueckl, J. G., Mikolinski, M., Raveh, M., Miner, C. S., \& Mars, F. (1997). Morphological priming, fragment completion, and connectionist networks. Journal of Memory and Language, 36, 382 405.

Schirmeier, M. K., Derwing. B. L., \& Libben, G. (2004). Lexicality, morphological structure, and semantic transparency in the processing of German ver-verbs: The complementarity of on-line and off-line evidence. Brain and Language, 90, 74-87.

Schreuder, R., \& Baayen, R. H. (1995). Modeling morphological processing. In L. B. Feldman (Ed.), Morphological aspects of language processing (pp. 131-154). Hillsdale, NJ: Lawrence Erlbaum Associates.

Schriefers, H., Zwitserlood, P., \& Roelofs, A. (1991). The identification of morphologically complex words: Continuous processing or decomposition? Journal of Memory and Language, 30, 26-47.

Schwarzwald, O. (2003). Transition in modern Hebrew word formation: From discontinuous to linear formation. In E. Hajicová, A. Kotesovcová, \& J. Mírovský (Eds.), Proceedings of the XVII International Congress of Linguists. Prague: Matfyzpress.

Segui, J., \& Grainger, J. (1990). Priming word recognition with orthographic neighbors: Effects of relative prime-target frequency. Journal of Experimental Psychology: Human Perception and Performance, 16, 65-76.

Smolka, E., Zwitserlood, P., \& Rösler, F. (2007). Stem access in regular and irregular inflection: Evidence from German participles. Journal of Memory and Language, 57, 325-347.

Stanners, R. F., Neiser, J. J., Hernon, W. P., \& Hall, R. (1979). Memory representation for morphologically related words. Journal of Verbal Learning and Verbal Behavior, 18, 399-412.

Stolz, J. A., \& Feldman, L. B. (1995). The role of orthographic and semantic transparency of the base morpheme in morphological processing. In L. B. Feldman (Ed.), Morphological aspects of language processing (pp. 109-129). Hillsdale, NJ: Lawrence Erlbaum Associates.

Taft, M. (2003). Morphological representation as a correlation between form and meaning. In E. Assink \& D. Sandra (Eds.), Reading complex words (pp. 113-137). Amsterdam: Kluwer.

Taft, M. (2004). Morphological decomposition and the reverse base frequency effect. Quarterly Journal of Experimental Psychology, 57A, 745-765.

Taft, M., \& Kougious, P. (2004). The processing of morpheme-like units in monomorphemic words. Brain and Language, 90, 9-16. 
Taft, M., \& Zhu, X. (1995). The representation of bound morphemes in the lexicon: A Chinese study. In L. B. Feldman (Ed.), Morphological aspects of language processing (pp. 293-316). Hillsdale, NJ: Lawrence Erlbaum Associates.

Velan, H., Frost, R., Deutsch, A., \& Plaut, D. (2005). The processing of root morphemes in Hebrew: Contrasting localist and distributed accounts. Language and Cognitive Processes, 20, 169-206.

Wegener, H. (2003). Entstehung und Funktion der Fugenelemente im Deutschen, oder: warum wir keine *Autosbahn haben [Origin and function of linking elements in German, or: why there is no *highsway]. Linguistische Berichte, 196, 425-457.

Zwitserlood, P., Drews, E., Bolwiender, A., \& Neuwinger, E. (1996). Kann man Geschenke umbringen? Assoziative Bahnungsexperimente zur Bedeutungsheterogenität von Verben [Can presents be killed? Associative priming experiments on the heterogeneous meaning of verbs]. In C. Habel, S. Kanngießer, \& G. Rickheit (Eds.), Perspektiven der kognitiven Linguistik (pp. 211232). Opladen: Westdeutscher Verlag 
APPENDIX

Stimulus material of Experiments 1 and 2

\begin{tabular}{|c|c|c|c|c|c|}
\hline Target & $-M+S$ & $+M+S$ & $+M-S$ & Orthographic & Unrelated \\
\hline $\begin{array}{l}\text { bleiben } \\
\text { fangen }\end{array}$ & $\begin{array}{l}\text { bestehen } \\
\text { jagen }\end{array}$ & $\begin{array}{l}\text { zurückbleiben } \\
\text { auffangen }\end{array}$ & $\begin{array}{l}\text { unterbleiben } \\
\text { unterfangen }\end{array}$ & $\begin{array}{l}\text { bleichen } \\
\text { fahnden }\end{array}$ & $\begin{array}{l}\text { senken } \\
\text { genießen/ } \\
\text { schminken }\end{array}$ \\
\hline finden & suchen & zurückfinden & abfinden & finten & malen \\
\hline fliegen & flattern & zurückfliegen & auffliegen & fließen & husten \\
\hline gehen & spazieren & fortgehen & angehen & gelten & fördern \\
\hline halten & stoppen & anhalten & enthalten & hallen & täuschen \\
\hline heben & stemmen & aufheben & beheben & hegen & spülen \\
\hline holen & bringen & zurückholen & erholen & holpern & quatschen \\
\hline hören & lauschen & anhören & aufhören & höhnen & rupfen \\
\hline kneifen & zwicken & zusammenkneifen & verkneifen & keifen & läuten \\
\hline kommen & nahen & mitkommen & umkommen & kämmen & schaden \\
\hline laufen & rennen & fortlaufen & unterlaufen & lausen & krachen \\
\hline legen & betten & ablegen & widerlegen & lesen & möchten/filtern \\
\hline machen & tun & vormachen & vermachen & macken & erhalten/bellen \\
\hline nehmen & geben & zurücknehmen & benehmen & necken & vergessen/kochen \\
\hline ordnen & sortieren & einordnen & verordnen & orten & rotieren/heilen \\
\hline pfeifen & singen & auspfeifen & verpfeifen & pfeffern & drücken \\
\hline raten & rätseln & beraten & verraten & rasen & spucken \\
\hline scheuern & schrubben & aufscheuern & verscheuern & schauern & ärgern \\
\hline schicken & senden & verschicken & anschicken & schocken & erlauben/hupen \\
\hline schießen & feuern & zurückschießen & vorschießen & schielen & wandern \\
\hline schlagen & prügeln & zuschlagen & unterschlagen & schlafen & wühlen \\
\hline schließen & öffnen & zuschließen & erschließen & schleißen & helfen/atmen \\
\hline schreiben & notieren & unterschreiben & zuschreiben & schreiten & warten/trennen \\
\hline schwimmen & baden & losschwimmen & verschwimmen & schwemmen & quieken \\
\hline schwingen & pendeln & nachschwingen & erschwingen & schwinden & zweifeln \\
\hline sehen & schauen & ansehen & versehen & sehnen & kleben \\
\hline setzen & stellen & aufsetzen & entsetzen & stelzen & glauben/backen \\
\hline sprechen & reden & ansprechen & entsprechen & sprengen & biegen/parken \\
\hline stechen & piken & ausstechen & bestechen & stecken & gießen \\
\hline stehlen & klauen & bestehlen & fortstehlen & strahlen & $\begin{array}{l}\text { provozieren/ } \\
\text { rudern }\end{array}$ \\
\hline steuern & lenken & zusteuern & versteuern & streunen & klopfen \\
\hline stürzen & stolpern & abstürzen & bestürzen & stürmen & reichen/dichten \\
\hline tragen & schleppen & forttragen & vortragen & trügen & schmelzen \\
\hline treten & trampeln & zertreten & abtreten & treffen & gähnen \\
\hline ziehen & zerren & zuziehen & erziehen & zielen & tarnen \\
\hline
\end{tabular}

Note. Experiments 1 and 2 comprised the same primes that were semantically related $(-\mathrm{M}+\mathrm{S})$, morphologically and semantically related $(+\mathrm{M}+\mathrm{S})$, and morphologically related $(+\mathrm{M}-\mathrm{S})$ to targets. Unrelated primes in Experiment 2 that differed from those in Experiment 1 are given as second word. Orthographically related primes occurred in Experiment 2. 